\title{
An Analytical Treatment of Channel-Morphology Relations
}

GEOLOGICAL SURVEY PROFESSIONAL PAPER 1288

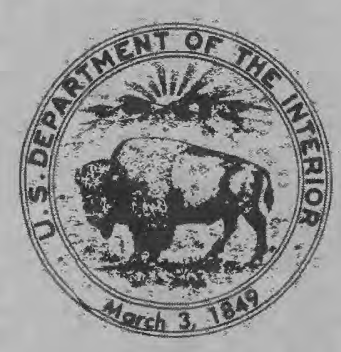





\section{An Analytical Treatment of Channel-Morphology Relations}

By W. R. OSTERKAMP, L. J. LANE, and G. R. FOSTER

GEOLOGICAL S URVEY PROFESSIONAL PAPER 1288






\title{
UNITED STATES DEPARTMENT OF THE INTERIOR \\ WILLIAM P. GLARK, Secretary
}

\author{
GEOLOGICAL SURVEY
}

Dallas L. Peck, Director

\footnotetext{
First printing 1983

Second printing 1984
}

Library of Congress Cataloging in Publication Data

Osterkamp, W, R.

An analytical treatment of channel-morphology relations.

(Geological Survey Professional paper ; 1288)

Bibliography: $\mathbf{p}$.

1. Channels (Hydraulic engineering) 2. Stream measurements. I. Lane, L. J. II. Foster, G. R. III. Title. IV. Series.

$\begin{array}{llll}\text { TC175.088 } & 1983 & 551.3^{\prime} 5 & 83-600312\end{array}$

For sale by the Distribution Branch, U.S. Geological Survey, 604 South Pickett Street, Alexandria, VA 22304 


\section{TABLES}

TABLE 1. Comparison of theoretically developed power-function exponents proposed by investigators

2. Power relations of width to discharge developed from field data of channels in the Western United States and grouped by width-depth ratios

3. Calculated and assumed values of $d, j_{1}$ through $j_{6}, b, f, m, z$, and $y$, for width-depth ratios of 5 to 1,000

4. Geometry-discharge data from natural stream channels with stable discharge

\section{SYMBOLS}

C Coefficient to hydraulic radius in the Chézy equation

$D \quad$ Mean channel depth

$G \quad$ Channel gradient

$P \quad$ Wetted perimeter of a channel section

$Q \quad$ Mean discharge of the water-sediment mixture

$Q_{i} \quad$ Instantaneous discharge of the water-sediment mixture

$R \quad$ Hydraulic radius

$S C \quad$ Silt-clay content of channel material

$V \quad$ Mean velocity of the water-sediment mixture

$W \quad$ Channel width

a Coefficient to discharge in the power relation between channel width and mean discharge

$a^{\prime} \quad$ Coefficient to the independent variables in the power relation between channel width and channel gradient, the Manning roughness coefficient, and mean discharge

Exponent to discharge in the power relation between channel width and mean discharge

c Coefficient to discharge in the power relation between mean channel depth and mean discharge

$c^{\prime}$ Coefficient to the independent variables in the power relation between mean channel depth and channel gradient, the Manning roughness coefficient, and mean discharge

d Exponent to proportional distance in the assumed power relation between normalized shear stress and proportional distance along the wetted perimeter of a channel selection

$d_{s 0} \quad$ Sediment particle size at which 50 percent of the distribution is finer

$f \quad$ Exponent to discharge in the power relation between mean channel depth and mean discharge

$j_{1} \quad$ Simplified exponent, equal to $(3 d+3) /(8 d+3)$, to a unitsconversion constant, to the Manning roughness coefficient, and to mean discharge; in the power relation between channel width and a units-conversion constant, the product of a shearstress coefficient and the specific weight of a water-sediment mixture, critical shear stress, channel gradient, the Manning roughness coefficient, and mean discharge

$j_{2} \quad$ Simplified exponent, equal to $5 /(8 d+3)$, to the product of a shear-stress coefficient and the specific weight of a watersediment mixture and to critical shear stress; in the power relation between channel width and a units-conversion constant, the product of a shear-stress coefficient and the specific weight of a water-sediment mixture, critical shear stress, channel gradient, the Manning roughness coefficient, and mean discharge

$j_{3} \quad$ Simplified exponent, equal to $(7-3 d) /(16 d+6)$, to gradient in the power relation between channel width and a units-conversion constant, the product of a shear-stress coefficient and the specific weight of a water-sediment mixture, critical shear stress, channel gradient, the Manning roughness coefficient, and mean discharge $j_{4} \quad$ Simplified exponent, equal to $3 d /(8 d+3)$, to a units-conversion constant, to the Manning roughness coefficient, and to mean discharge; in the power relation between mean channel depth and a units-conversion constant, the product of a shear-stress coefficient and the specific weight of a water-sediment mixture, critical shear stress, channel gradient, the Manning roughness coefficient, and mean discharge

$j_{\mathrm{s}} \quad$ Simplified exponent, equal to $3 /(8 d+3)$, to the product of a shear-stress coefficient and the specific weight of a watersediment mixture, and to critical shear stress; in the power relation between mean channel depth and a units-conversion constant, the product of a shear-stress coefficient and the specific weight of a water-sediment mixture, critical shear stress, channel gradient, the Manning roughness coefficient, and mean discharge

$j_{6} \quad$ Simplified exponent, equal to $(3 d+3) /(16 d+6)$, to gradient in the power relation between mean channel depth and a unitsconversion constant, the product of a shear-stress coefficient and the specific weight of a water-sediment mixture, critical shear stress, channel gradient, the Manning roughness coefficient, and mean discharge

$k$ Coefficient to discharge in the power relation between mean velocity of the water-sediment mixture and mean discharge

$k^{2} \quad$ Simplified coefficient, equal to 1.0 , that is the product of the coefficients $a, c$, and $k$ in the power relations of width, depth, and velocity with mean discharge

$m$ Exponent to discharge in the power relation between mean velocity of the water-sediment mixture and mean discharge

Roughness coefficient of the Manning equation

Coefficient to proportional distance in the assumed power relation between normalized shear stress and proportional distance along the wetted perimeter of a channel section

Coefficient to discharge in the power relation between the roughness coefficient of the Manning equation and mean discharge

Coefficient to discharge in the power relation between channel gradient and mean discharge

Distance along the wetted perimeter of a channel section

Proportional distance, equal to $x / P$

Exponent to discharge in the power relation between the roughness coefficient of the Manning equation and mean discharge

Exponent to discharge in the power relation between the channel gradient and mean discharge

Specific weight of the water-sediment mixture

$\frac{\gamma}{\tau} \quad$ Average shear stress, the product of the specific weight of the water-sediment mixture, channel gradient, and mean channel depth

$\tau_{m} \quad$ Maximum bed shear stress at the center of a channel section

Critical shear stress

Units-conversion constant in the Manning equation 


\title{
AN ANALYTICAL TREATMENT OF CHANNEL-MORPHOLOGY RELATIONS
}

\author{
By W. R. OSTERKamp, L. J. LANE ${ }^{1}$, and G. R. Foster ${ }^{1}$
}

\begin{abstract}
For a specified flow rate, the properties of channel width, mean depth, mean flow velocity, gradient, and roughness often are related to discharge by empirically developed power functions. Equations were derived that provide an analytical, or semitheoretical, basis for the empirical relations. The equations, which were calibrated and tested using field data, differ from previously derived power functions by incorporating variable exponents dependent on the shear-stress distribution along the channel section. Variable exponents permit the consideration of the entire range of natural channel geometries, including those of very wide braided channels that otherwise could not be described adequately by power functions. The derivation of these exponents is based on the continuity equation, the Manning equation, and an assumed equation for shear-stress distribution expressed in terms of channel width-depth ratio. By this approach, width-depth ratios are employed as surrogates for the channel sediment characteristics and the shearstress distribution.

The equations were calibrated using channel data from the western half of the United States. The calibrated power equations were tested using data from relatively stable channels of the United States-in Ohio and southern Missouri-New Guinea, and Australia. Stable channels with steady discharge characteristics were selected for the testing to approximate the steady-state discharges assumed by the derivations. Results of the calibration and tests lead to generalizations concerning channel dynamics.
\end{abstract}

\section{INTRODUCTION}

The ancients observed that channels are molded by the water and sediment passing through them. In recent times attempts to quantify the channel changes that result from varying conditions of discharge have been made using concepts such as regime theory, hydraulic and channel geometry, and dynamic equilibrium.

Most efforts at quantification have been empirical and involve the use of power functions or similar simple equations to approximate the manner in which channel characteristics vary with discharge. The two sets of relations commonly developed in geomorphic studies have been (1) the variation of geometric and hydraulic variables (such as water surface or channel width and mean depth) with discharge or stage at a particular fixed channel cross section and (2) the variation of hydraulic (velocity, roughness) or geometric (width, depth, gradient) properties with discharge at different locations along a channel, measured on the basis of a common

${ }^{1}$ U.S. Department of Agriculture hydraulic or geomorphic reference level. The first set of relations generally is termed the "at-a-station" case, and the second, to which attention is limited in this paper, is the "downstream" case (Leopold and Maddock, 1953, p. 4). The basic mathematics and assumptions on which the empirical studies depend are given in numerous papers on the topic and, therefore, are given here in summary form only. Many of the papers cited here, however, provide background explanations of the hydraulic- and channel-geometry methods.

This paper provides a semitheoretical basis for the use of power functions with variable exponents to describe the shapes of natural alluvial stream channels. Many of the empirical studies have defined the "downstream" changes of channel width, mean depth, and mean flow velocity as power functions of a discharge characteristic; the exponent values for each of the three power functions commonly have fallen in a limited range. As a result, approaches to definition of theoretical exponent values for the three power functions have concentrated on yielding single values representative of the limited range of values that the empirical studies typically provide. Variation in the exponent values for these empirical power functions does occur, however, and it cannot be reasonably assumed that single values of the exponents describe the range of conditions found in natural alluvial stream channels. The wide ranges of possible exponent values become apparent when the geometries of unusually wide or narrow channels are considered. Unlike previous theoretical or semitheoretical analyses of geometry-discharge relations, therefore, the present paper treats the entire range of geometries found in natural alluvial channels and proposes power functions with variable exponents partially based on theoretical considerations.

The mathematical approach of this paper is termed "analytical" instead of theoretical because the equations were developed, in part, from empirical relations and were calibrated using field data. The geometry data used for the calibration, collected from the western half of the United States, are summarized in an empirical study proposing variable geometry-discharge relations (Osterkamp and Hedman, 1982); this study is the basis 
for the present analytical approach. The Western United States data, separated into groups for calibration (depending on channel width-depth ratio), yielded width-discharge power functions with exponents that increase as width-depth ratios increase. For some groups, however, the data were insufficient to define with confidence a unique empirical power relation. Consequently, the analytical power functions of this paper, calibrated with the field data from the Western United States, are supported further with field data from stable stream channels of southern Missouri and Ohio (in the United States), New Guinea, and Australia.

\section{PREVIOUS INVESTIGATIONS}

Hydraulic geometry, as defined by Leopold and Maddock (1953), is the description of the graphical relations between plot points of hydraulic characteristics. These characteristics include width and mean depth, measured at or from the water surface. Channel-geometry investigations evolved from the hydraulic-geometry concept as a method of indirectly estimating discharge characteristics at ungaged channel sites. In the downstream case, the channel-geometry technique differs from that of hydraulic geometry in that some channel properties are defined by measurements taken from a recognizable geomorphic reference level rather than relative to a particular stage. Because hydraulicgeometry data can be collected only at prevailing flow rates and stream stages, the downstream relations for a specified flow duration ordinarily must be determined from graphs of the at-a-site changes of width and depth with discharge. By the channel-geometry technique, the various geomorphic reference levels for most perennial stream channels can be related directly to limited ranges of flow duration or flood frequency. Thus, width data measured from the active-channel reference level (Osterkamp and Hedman, 1977, p. 256), which commonly approximates a stage representing mean discharge and a flow duration of roughly 15 percent, are typically related to values of mean discharge. Geometry data collected at the flood-plain level might be related to flood discharges with recurrence intervals of 2 years.

This difference between the hydraulic-geometry and channel-geometry techniques enhances the comparability of data from diverse sites, but normally requires that a relation for mean velocity $(V)$ must be developed indirectly. In this paper, width $(W)$, mean-depth $(D)$, and gradient $(G)$ data are referred to the active-channel reference level, which, for perennial and intermittent streams, is coincident with the lower limit of perennial vegetation. The resistance to flow of an active-channel section is treated as a variable that decreases in the downstream direction (Leopold and Maddock, 1953, p. 27 ) and is characterized by the roughness coefficient, $n$, of the Manning equation. The power equations typically defined by empirical studies of channel geometry are the following:

$$
\begin{aligned}
W & =a Q^{b} \\
D & =c Q^{f} \\
V & =k Q^{m} \\
G & =t Q^{z} \\
n & =r Q^{y}
\end{aligned}
$$

where $a, c, k, t$, and $r$ are coefficients, and $b, f, m, z$, and $y$ are exponents. Because discharge $(Q)$ is the product of width, mean depth, and mean velocity (the continuity equation for streamflow), the product of $a, c$, and $k$ and the sum of $b, f$, and $m$ must both equal unity (Leopold and Maddock, 1953).

A basic goal of most empirical hydraulic- and channelgeometry studies has been evaluation of the exponents of equations 1 through 5, particularly those of the first three: $b, f$, and $m$. Results have varied, but generally values have fallen in the range of 0.45 to 0.55 for $b, 0.3$ to 0.4 for $f$, and 0 to 0.2 for $m$. A wide range of empirical values for $z$, mostly -0.1 to -0.5 , have been reported. The value of $y$ probably has received the least attention but is commonly thought to range from about 0 to -0.15 .

There are several possible causes of the inconsistent results for identifying the exponents of equations 1 through 5. Two of the principal causes are (1) the use of regional or local data sets that represent limited ranges of the variables that possibly complicate the geometrydischarge relations, and (2) the specific lack of a method, in most studies, to discriminate variability of bank cohesiveness or stability. In the analytical treatment of this paper, the characteristics of bed and bank sediment are not considered directly but are included in the derivation as width-depth ratios. It is assumed that for any set of size characteristics for sediment forming the bed and banks of a channel, a characteristic width-depth ratio for relatively stable or adjusted channel conditions can be identified. Through the remainder of this paper, therefore, consideration of width-depth ratios implies specified conditions of sediment forming the channel perimeter.

The likelihood that the size distribution and cohesiveness of material forming the channel perimeter affects the geometry-discharge relations has been recognized repeatedly (as examples, see Leopold and Maddock, 1953; Schumm, 1960; Wolman and Brush, 1961; Knighton, 1974; Smith, 1974; Hedman and Kastner, 1977; Williams, 1978; and Mosley, 1981). Nevertheless, this possible cause of variation has been neglected in most empirical studies, and a single value for each exponent generally was reported. The use of single values causes little difficulty for the majority of alluvial chan- 
nels that are moderately cohesive, but empirical data, as well as theoretical considerations, suggest that use of single values leads to substantial error for channels formed of either highly cohesive or noncohesive material (Schumm, 1960; Knighton, 1974; and Williams, 1978).

The main purpose of this paper is to propose a derivation of the width, depth, and velocity exponents, $b, f$, and $m$, and to suggest that the value of each varies with the material forming the channel perimeter. The approach used in this paper extends the utility of several previous derivations by demonstrating that ranges of values for $b, f$, and $m$ are justified on other than a purely empirical basis. Thus, the relations presented here can be used to anticipate the geometry resulting from specified conditions of water and sediment discharge or, conversely, for estimating discharge characteristics if channel conditions are known.

Substantial literature concerning the various power functions (eqs. 1-5) has accumulated. Most of the papers provide empirical evaluations of one or more of the exponents, but they are too numerous to provide a thorough discussion here. Among those that either are generally regarded as particularly significant or are especially pertinent to the present study are papers by Kennedy (1895), Lindley (1919), Lacey (1930), Lane (1937, 1957), Leopold and Maddock (1953), Wolman (1955), Blench (1957), Schumm (1960), Brush (1961), Hedman and Kastner (1977), Osterkamp (1978), and Osterkamp and Hedman (1982). A comprehensive list of references pertaining to hydraulic and channel geometry is presented by the Task Committee of the American Society of Civil Engineers (1982) on relations between morphology of small streams and sediment yields.

A variety of approaches has been used to replicate theoretically or semitheoretically the experimental geometry-discharge relations. Although the various methods use a wide range of equations and assumptions to define channel morphology, they all rely on the continuity equation $(Q=W D V)$ and one or more additional relations to yield simultaneous solutions. Most approaches assume that the variables in the continuity equation can be expressed as power functions (eqs. 1-3). The assumption seems justified for the ranges of data normally considered, but is poorly founded for very small discharges (Osterkamp and Hedman, 1982). Use of the assumption, however, provides a second equation because the expansion of the continuity equation to power form requires that the sum of the exponents equal unity:

$$
b+f+m=1
$$

Table 1 provides comparisons of the theoretically developed power-function exponents (eqs. 1 to 5) pro-
TABLE 1.-Comparison of theoretically developed power-function exponents proposed by investigators

[Dashed entry means a value is not available; some values have been rounded to two significant figures]

\begin{tabular}{|c|c|c|c|c|c|}
\hline Investigator & $\begin{array}{c}\text { Width } \\
\text { exponent } \\
b\end{array}$ & $\begin{array}{c}\text { Depth } \\
\text { exponent } \\
f\end{array}$ & $\begin{array}{l}\text { Velocity } \\
\text { exponent } \\
m\end{array}$ & $\begin{array}{c}\text { Gradient } \\
\text { exponent } \\
z\end{array}$ & $\begin{array}{c}\text { Roughness } \\
\text { exponent } \\
y\end{array}$ \\
\hline \multicolumn{6}{|l|}{ Leopold and } \\
\hline Langbein (1962) _ & 0.55 & 0.36 & 0.09 & -0.74 & -0.22 \\
\hline Langbein (1964) -- & .53 & .37 & .10 & -.73 & -.45 \\
\hline Tou Kuo-jen (1964) & .56 & .33 & .11 & $-\infty$ & --- \\
\hline $\begin{array}{l}\text { Engelund and } \\
\text { Hansen (1967) }\end{array}$ & $5 ?$ & & 16 & 21 & \\
\hline Brebner and & .02 & .02 & .10 & -.21 & \\
\hline Wilson (1967) & .47 & .35 & .18 & -.12 & ---- \\
\hline Li Ruh-ming (1974) & .46 & .46 & .08 & -.46 & --- \\
\hline Smith (1974) ___ & .64 & .27 & .09 & -.18 & $-\infty$ \\
\hline Parker (1979) _-_.. & .50 & .42 & .08 & -.41 & --- \\
\hline $\begin{array}{l}\text { Lane and Foster } \\
(1980)^{1}\end{array}$ & .46 & .46 & .08 & $-m$ & $--\infty$ \\
\hline
\end{tabular}

Triangular cross section.

posed by Leopold and Langbein (1962), Langbein (1964), Tou Kuo-jen (1964), Engelund and Hansen (1967), Brebner and Wilson (1967), Li Ruh-ming (1974), Smith (1974), Parker (1979), and Lane and Foster (1980). In general, the values should be compared with caution because the assumptions, characteristic discharge, and type channel that led to the exponents are variable. Despite these problems, the values for $b$, the width exponent, range only from 0.46 to 0.64 . The $f$ and $m$ values, for depth and velocity, derived from various theoretical approaches, also show relative consistency (table 1) and agree well with the majority of the empirically developed power functions. The values of $z$ and $y$, for channel gradient and roughness, however, show substantial ranges in table 1 . These exponents apparently are much more sensitive to the assumptions of a derivation, particularly the water- and sediment-flow characteristics used, than are the width, depth, and velocity exponents. A large range of empirical values for $z$, for example, has been reported. The smallest values, as low as 0.0 , generally have been associated with low discharge rates, as represented by rill erosion (Lane and Foster, 1980) and controlled inflow in small channels (Ackers and Charlton, 1971). Values of $z$ as great as -1.07 have been related to stable armored channels, such as Brandywine Creek in Pennsylvania, at the bankfull stage (Wolman, 1955, p. 26).

The basic form of a time-dependent model that recognizes channel morphology as the result of all discharges transmitted by the channel was presented by Pickup and Rieger (1979). Although this model does not provide specific derivations of geometry power functions, it is pertinent to the present analysis because the model proposes that channel size and shape are not unique to a dominant discharge. Pickup and Rieger suggested that channel geometry tends to fluctuate about a mean condi- 
tion, and that the geometry is partly dependent on the recent flood history of the stream. This view is consistent with empirical data by Schumm and Lichty (1963), Burkham (1972), and Osterkamp and Hedman (1982).

\section{DEVELOPMENT OF EQUATIONS}

The previously cited investigators of theoretically developed power-function exponents employed a variety of techniques and assumptions to show that the empirically defined power equations for hydraulic and channel geometry are reasonably accurate. A nearly common deficiency of the previous analyses, however, has been a generalized treatment for all alluvial channels or else a specific treatment for a selected range of alluvial channels. In both cases the result has been single exponent values of limited utility. The derivations are well designed to describe geometry-discharge relations of stable, well-formed channels, but are poorly equipped to consider less common channel types, such as those of braided channels. The derivation presented here develops geometry-discharge relations applicable to the range of alluvial-channel conditions normally found in nature.

\section{ASSUMPTIONS}

All hydraulic- and channel-geometry relations are developed from the continuity equation for the instantaneous discharge $\left(Q_{i}\right)$ of the water-sediment mixture:

$$
Q_{i}=W D V,
$$

where $D$ represents mean depth and $V$ represents mean velocity. When numerous downstream sites are considered, the simplifying assumptions are made that (1) the rates of change of the logarithms of $W, D$, and $V$ with the logarithm of $Q_{i}$ are constant (that is, plots of $W$, $D$, and $V$ against $Q_{i}$ yield straight rather than curved lines on logarithmic coordinates), and (2) these rates of change can be expressed by a multiple power-function equation:

$$
Q_{i}=k^{\prime} Q_{i}{ }^{b} Q f Q_{i}{ }^{m},
$$

where the coefficient, $k^{\prime}$, is the product $a \times c \times k$ and is equal to 1.0 , and the sum of the exponents, $b, f$, and $m$, also equals 1.0 (eqs. 1, 2, 3, and 6). This second assumption is reasonable only if $Q_{i}$ represents the same flow characteristic for all sites considered. In this paper, it is assumed that discharge, $Q$, is steady or varies through a small range so that $Q_{i}, Q$, and mean discharge are essentially the same. Width and mean-depth values pertain to measurements taken at the water surface or the corresponding geomorphic channel feature at mean (steadystate) discharge. Gradient is measured at the channel section, and roughness is a complex function of many factors including the channel geometry and the particlesize distribution of the material forming the channel perimeter (Limerinos, 1969, p. 6).

The derivation that follows results in expanded forms of equations 1 and 2, the power functions for width and depth. By the continuity equation, a power function for mean velocity (eq. 3) is also defined. Evaluation of the derived equations 1 and 2 must be made implicitly because the coefficients $a$ and $c$ incorporate a critical shear-stress term, as well as the coefficients $t$ and $r$ for the gradient (eq. 4) and roughness (eq. 5) relations. Calculation of the exponents of the width and depth relations requires values for the gradient and roughness exponents, $z$ and $y$ (eqs. 4 and 5). An iterative evaluation is possible by employing established (assumed) empirical width-discharge relations and an assumed relation between the roughness and depth exponents ( $y$ and $f$ ).

Other assumptions necessary to the variable-exponent derivation presented here are the following:

1. Flow-resistance equations (the Manning and Chézy eqs.) are accurate through the ranges of discharges and channel conditions considered.

2. Channel-roughness variation in the downstream directon for steady-state discharge (and a condition of constant particle-size distributions of the material forming the channel perimeter in the downstream direction) is dependent only on the geometry (width, mean depth, and gradient) of the channel. Bed-form roughness is assumed constant in the downstream direction; particle-size distributions of channel sediment are not necessarily assumed constant in the downstream direction.

3. For consideration of shear-stress distribution in a channel section, the channel width is sufficiently large relative to depth that hydraulic radius $(R)$ can be treated as approximately equal to mean depth.

4. All channels are assumed to be rectangular in shape and are subject to a relation between maximum and mean shear stress of

$$
\tau_{m} / \bar{\tau}=1+(W / D)^{-0.60},
$$

where $\tau_{m}$ is the maximum bed shear stress at the center of the channel, and $\bar{\tau}$ is the average shear stress across the channel. This assigned equation approximates the relation between experimental shear-stress and geometry data of Chow (1959), Kartha and Leutheusser (1970), and Prasad and Alonso (1976). Justification for the use of equation 9 is provided in a later section.

5. Particle sizes of the sediment forming the wetted perimeter of a rectangular channel section vary to a maximum at the channel center; these particle sizes are compatible with associated variations in the distributions of velocity and shear stress. 
6. An equilibrium channel geometry (neither aggrading nor degrading) occurs when the shear stress at the lower corners of the rectangular channel section equals the critical shear stress for the given channel-bank material. It is assumed, therefore, that for specified conditions of discharge and particle sizes of channel material, an equilibrium condition signifies a specific width-depth ratio. By designating discharge and geometry (width-depth ratio), the need to consider explicitly particle sizes of channel material is eliminated.

All of the above assumptions were made, either implicitly or explicitly, in one or more of the theoretical investigations listed in table 1 . For example, the assumption of power relations with discharge generally is made for the geometry variables (eqs. 1 to 5). Power relations describing shear-stress distributions also were assumed by Rohlf and Meadows (1980) and by Lane and Foster (1980), although the forms of equations differ from that assumed here (eq. 9). Rectangularly shaped channels commonly are considered when analyzing shear-stress data; these channels are assumed in the models of Brebner and Wilson (1967) and Lane and Foster (1980). Empirical flow-resistance equations or coefficients are incorporated into most of the derivations summarized by table 1 .

\section{PROCEDURE}

The power-function derivations presented here, one for width and one for depth, involve four steps: (1) combining the continuity and Manning equations into a single equation involving both width and depth; (2) solving the assumed shear-stress distribution equation of a channel section for depth as a function of width (or vice versa); (3) substituting the result into the combined continuity-Manning relation to obtain a multiple power function for downstream changes of width or depth; and (4) substituting the required exponent values for the gradient and roughness power functions iteratively into the multiple power-function equations for width and depth until results consistent with empirical gradient relations and the Chézy equation are obtained. In other words, downstream equations for width and depth are developed as functions of the discharge, critical shear stress, gradient, and roughness at a channel section. To express the equations in the form of equations 1 and 2 , all terms except that for discharge are included in the coefficient. Thus, in the end (eqs. 1 and 2), discharge remains as the sole independent variable, but its value depends on the input values for shear-stress distribution and the gradient and roughness exponents of equations 4 and 5 .

Returning to the first step in greater detail, the discharge form of the Manning equation is simplified by assuming that depth and hydraulic radius, $R$, of a channel section are nearly equal:

$$
Q=\frac{\psi}{n} G^{1 / 2} W D^{5 / 3} \text {. }
$$

The value of the constant $\psi$ depends on the system of units used (for metric units, $\psi=1.0$; in U.S. customary units, $\psi \simeq 1.49$ ); other symbols are as previously defined. Rearranging gives

$$
W^{3 / 5} D=\left[\frac{n Q}{\psi G^{1 / 2}}\right]^{3 / 5}
$$

In order to consider shear-stress distribution in the channel section, an assumed distribution is solved in terms of width and depth and then combined with equation 11 . An assumed rectangular channel has steady discharge, a width $W$, and a depth $D$. The wetted perimeter, $P$, is then $W+2 D$. Let $x$ equal the distance from the water's edge to any point on the wetted perimeter up to the channel center. The proportional distance, $x_{*}$, along the wetted perimeter is the ratio of $x$, the distance along the wetted perimeter, to the length of the wetted perimeter:

$$
x_{*}=x / P \text {. }
$$

The proportional distance, $x_{*}$, thus ranges from 0 at the water's edge to 0.5 at the midline of the channel. The width-depth ratio of most natural stream channels exceeds 12 , which permits the simplification that width nearly equals wetted perimeter.

The normalized shear stress, $\tau\left(x_{*}\right) / \bar{\tau}$, at any point along the wetted perimeter is a function of the proportional distance:

$$
\tau\left(x_{*}\right) / \bar{\tau}=F\left(x_{*}\right) .
$$

If the function, $F\left(x_{*}\right)$ is assumed to be a power function:

$$
\tau\left(x_{*}\right) / \bar{\tau}=p\left(x_{*}\right)^{d},
$$

where $p$ is a coefficient, $d$ is an exponent, and $0<x_{*} \leq 0.5$.

In order to maintain a steady-state channel condition, the shear stresses along the banks must be less than, or equal to, the critical shear stress of the bank sediment, thereby assuring no bank erosion or channel widening. The shear stresses at points along the bed, however, must equal or exceed the critical shear stress for bed sediment in order that bed-load movement is maintained without causing aggradation. The transition between the cohesive material in the bank and the mobile particles on the bed occurs at the intersection of the vertical bank and the bed. At this point, which is equivalent to $x_{*}=D / W$, the shear developed by the flow equals the critical shear, $\tau_{c}$, regardless of the character and mor- 
phology of the bed material. Thus, at the intersection, substitution into equation 14 yields

$$
\tau_{c} / \gamma G D=p(D / W)^{d},
$$

where $\bar{\tau}$ equals $\gamma G D$, and $\gamma$, the specific weight of the water-sediment mixture, is disregarded as being nearly equal to 1.0 grams per cubic centimeter. After solving equation 15 for depth and substituting the result into equation 11, equation 11 is solved for width:

$$
W=\left[\frac{\gamma G p}{\tau_{c}}\right]^{\left(\frac{5}{8 d+3}\right)}\left[\frac{n Q}{\psi G^{1 / 2}}\right]^{\left(\frac{3 d+3}{8 d+3}\right)}
$$

Letting $j_{1}=(3 d+3) /(8 d+3), \quad j_{2}=5 /(8 d+3)$, and $j_{3}=(7-3 d) /(16 d+6)$, equation 16 can be simplified to

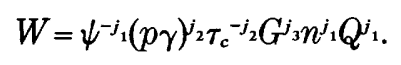

Similarly, expressing equation 15 in terms of width, substituting in equation 11 and solving for depth yields

$$
D=\psi^{-j_{4}}(p \gamma)^{-j_{5}} \tau_{c}^{j_{5}} G^{-j_{6}} n^{j_{4}} Q^{j_{4}}
$$

where $j_{4}=3 d /(8 d+3), \quad j_{5}=3 /(8 d+3)$, and $j_{6}=(3 d+6)$ $(16 d+6)$.

Having expressed equations 17 and 18 in terms of $p$ and $d$, the coefficient and exponent, respectively, of the shear-stress power function (eq. 14), it is necessary to evaluate $p$ and $d$ before geometry relations can be computed. Because the shear-stress distribution is symmetrical about the channel center line $\left(x_{*}=0.5\right)$, by definition:

$$
\bar{\tau}=\frac{1}{0.5} \int_{0}^{0.5} \tau\left(x_{*}\right) d x_{*} .
$$

Substitution for $r\left(x_{*}\right)$ from equation 14 and solving yields:

$$
p=2^{d}(d+1) .
$$

If $\tau_{m}$ is the maximum shear stress at the channel center $\left(x_{*}=0.5\right)$,

$$
\left(\tau_{m} / \bar{\tau}\right)=p(0.5)^{d} .
$$

Substituting for $p$ from equation 20 and rearranging yields

$$
d=\left(\tau_{m} / \bar{\tau}\right)-1.0
$$

Considering the perimeter of half of a rectangular channel section, the normalized shear stress, $\tau\left(x_{*}\right) / \bar{\tau}$, must have a mean value of 1.0 . Although specific to the width-depth ratios and limited by the assumptions made previously, representative normalized shear-stress distributions along the channel beds are shown in figure 1. From equation $22, \tau_{m} / \bar{\tau}$ must be equal to or greater than 1.0, and from analytical and experimental data on shear-stress distributions (Chow, 1959, p. 169; Replogle and Chow, 1966; Kartha and Leutheusser, 1970, p. 1475; and Prasad and Alonso, 1976), it should not range as high as 2.0. Data on the ratios between maximum and average shear stresses as functions of width-depth ratios up to 12.5 (from Chow, 1959, p. 169, Kartha and Leutheusser, 1970, and Prasad and Alonso, 1976) are plotted in figure 2. The data show that the normalized maximum shear stress has the greatest value when the width-depth ratio (for rectangular channels) is about 3 .

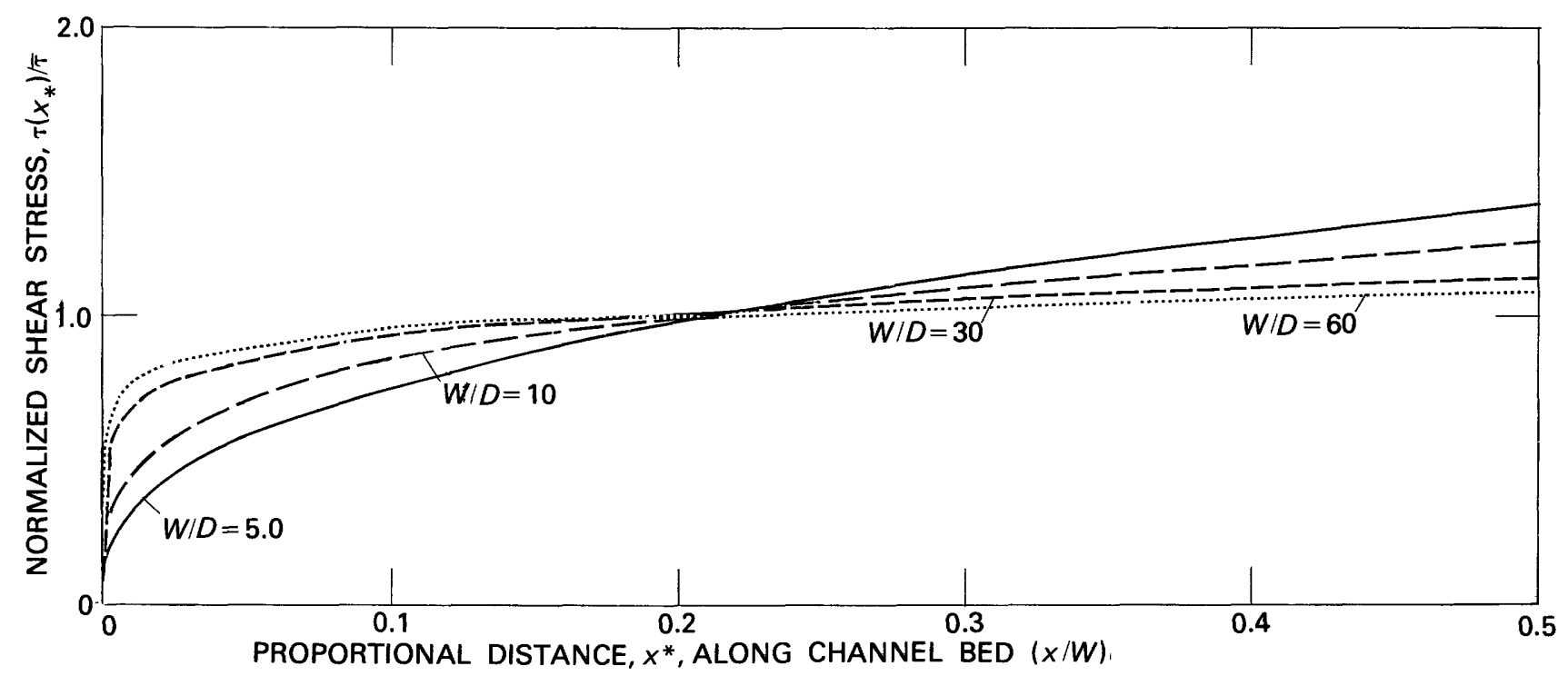

FIGURE 1.-Variation of normalized shear stress with proportional distance along half the perimeters of hypothetical alluvial channels. 


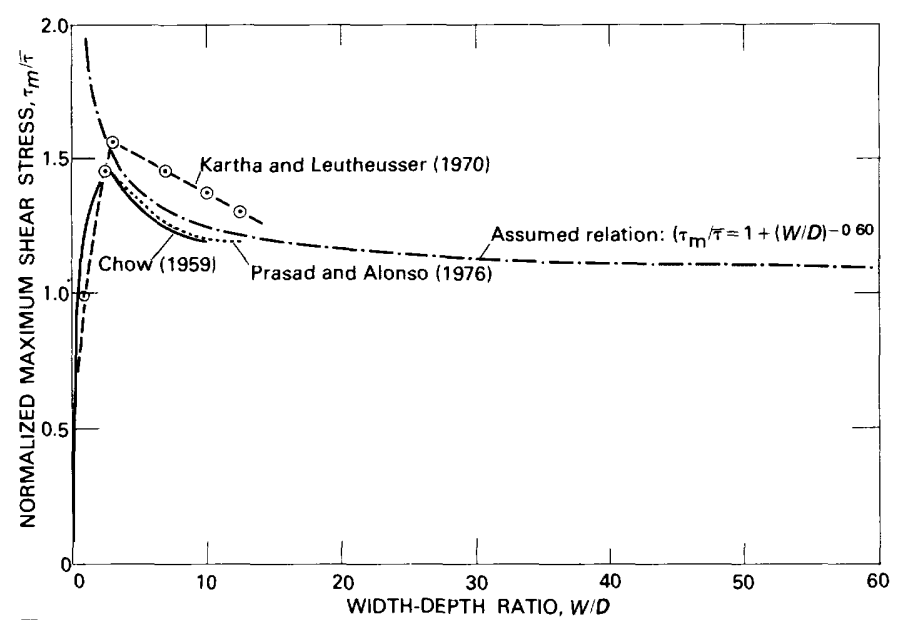

FiguRe 2. - Variation of normalized maximum shear stress at the midline of a rectangular channel, with width-depth ratio $(W / D)$ for analytical and experimental data, and for the assumed relation $\left(\tau_{m} / \tau\right)=1+(W / D)^{-0.60}$.

Field data justifying equation 9 also have been published for channels with width-depth ratios exceeding 12.5. For example, some of Bathurst's (1979) normalized shear-stress data for gravel-lined natural channel sections compare favorably with the curves of figure 2 . Because the Bathurst data were collected from natural channels that do not necessarily conform to the assumptions of this paper, the results are variable across channel sections and are not plotted in figure 2 .

With increasing values of width-depth ratio above 3.0 , the normalized maximum shear stress decreases asymptotically toward 1.0. With decreasing values of widthdepth ratio below 3.0, the normalized maximum shear stress in other studies declines toward 0 , whereas the assumed maximum shear stress in this paper approaches infinity. However, this portion of figure 2 is of minor consequence to the present discussion because the width-depth ratios of natural alluvial stream channels are usually much larger than 3.0 (for example, see data of Hedman and Kastner, 1977; and Osterkamp and Hedman, 1982). Thus, it is assumed that equation 9 leads to a reasonable description of the distribution of shear stresses across alluvial channels. From equations 9 and 22 , it follows that

$$
d=(W / D)^{-0.60},
$$

which is a necessary relation to solve equations 17 and 18. For the range of width-depth ratios expected in natural alluvial stream channels, values of $d$ vary from nearly 0 to about 0.4 , but values of $d$ for most alluvial channels fall between 0.1 and 0.3 (corresponding to width-depth ratios of roughly 50 and 7 , respectively).

In equations 17 and $18, \psi, p, \gamma$, and $\tau_{c}$ can be incorporated into the coefficients $a$ and $c$ of equations 1 and 2 . Gradient $(G)$ and roughness $(n)$, however, vary with width-discharge and depth-discharge relations, and these variables must be considered when evaluating the exponents $b$ and $f$. In other words, channel gradient and roughness are two of the five (eqs. 1 to 5) acknowledged degrees of freedom of self-adjusting channels (Williams, 1978, p. 2).

By defining coefficients $\alpha^{\prime}$ and $c^{\prime}$, respectively, equal to $\psi^{-j_{1}}(p \gamma)^{i_{2} \tau_{c}-j_{2}}$ and $\psi^{-j_{4}}(p \gamma)^{-j_{s}} \tau_{c}^{j_{5}}$, equations 17 and 18 are simplified to

and

$$
W=a^{\prime} G^{j_{3}} n^{j_{1}} Q^{j_{1}}
$$

$$
D=c^{\prime} G^{-j_{6}} n^{j_{4}} Q^{i_{4}} .
$$

By inserting the discharge terms for gradient and roughness from equations 4 and 5 , simplifying and defining $a^{\prime} t^{j_{3}} r^{j_{1}}$ and $c^{\prime} t^{j_{6}} r^{j_{4}}$, respectively, equal to $a$ and $c$ (eqs. 1 and 2), equations $17 \mathrm{a}$ and $18 \mathrm{a}$ are converted to

and

$$
W=a Q^{\left(j_{1}+z j_{3}+\nu j_{1}\right)}
$$

$$
D=c Q^{\left(j_{4}-x j_{6}+y j_{4}\right)} .
$$

As suggested by the range of exponents shown in table 1 , an accepted theoretical value for $z$ is not available. Empirical data from relatively stable alluvial channels (having well-formed banks), however, indicate a value for $z$ of -0.25 regardless of the particle-size characteristics of the material forming the channel perimeter (Lane, 1957; Osterkamp, 1978). This exponent is based on data from natural channels over wide ranges of mean discharge and gradient; the data were grouped according to similar characteristics of the channel material. For the downstream condition of stable channel sections formed of unchanging particle sizes, therefore, $z$ does not vary significantly from -0.25 . Instead, from one channel to another, differences in the gradient-discharge relation (eq. 4), due to differences in the particle-size distribution, are reflected in the coefficient, $t$ (Osterkamp, 1978). For very wide, braided channels, however, both theoretical considerations (for example, Leopold and Langbein, 1962, p. 12; Langbein, 1964, p. 309) and field evidence (Osterkamp and Hedman, 1982) suggest that $z$, as well as $f, m$, and $y$, must approach 0 as $b$ approaches 1.0 .

The bed-roughness exponent, $y$, is known, both from field investigations (Leopold and Maddock, 1953, p. 27; and Wolman, 1955, p. 27) and geometry relations (table 1 ), to be a generally small negative number when particle sizes of channel material do not change in the downstream direction. Although influenced by the widthdepth ratio and its rate of change with discharge, increasing discharge in the downstream direction generally results in decreasing surface area of the channel per unit volume of discharge and stream length. In other words, discharge tends to increase in the downstream 
direction at a greater rate than does the wetted perimeter. Thus, the frictional losses per unit volume of discharge decrease downstream, and a negative value for $y$ is required. If a channel is extremely wide relative to discharge ( $W / D>1,000$, for example), and depth and velocity do not increase measurably in the downstream direction ( $f$ and $m$ approach 0 ), the roughness exponent, $y$, also approaches 0 . Note, however, that the exponents of equations 24 and 25 are defined as functions of widthdepth ratio (eq. 23). Implicit results in equations 24 and 25 are that (1) particle sizes of channel material must change in the downstream direction in order to maintain the specified constant width-depth ratios, and (2) assumed $z$ and $y$ values based on unchanging particle sizes are not necessarily applicable.

The extent of the downstream change in bed roughness can be evaluated quantitatively in terms of depth from the Chézy equation:

$$
C \sim \frac{R}{n}^{0.167},
$$

where $C$ is a coefficient known as Chézy $C$. If $C$ is assumed constant and hydraulic radius is nearly equal to depth, the roughness and mean-depth terms are proportional. Substituting the discharge terms for depth from equation 2 and roughness from equation 5 , and defining $y$ as negative:

$$
y=-0.167 f \text {. }
$$

For channels of specified width-depth ratio (thereby known values of $d$ and $j_{1}$ through $j_{6}$ ) and by assuming a reasonable starting value for $y, f$ in equation 25 can be evaluated (where $z$ is designated and $f$ equals $\left.j_{4}-z j_{6}+y j_{4}\right)$. From the calculated value of $f$ and equation 27 , a new value of $y$ is computed. If the $y$-value calculated from equation 27 differs significantly from the assumed value, the procedure is repeated using the newly computed $y$ value as the assumed $y$ value for a reevaluation of $f$ in equation 25 . In this manner, two or three iterations should be sufficient to provide an assumed $y$ in equation 25 that is reasonably accurate by equation 27. After $y$ has been determined, it is used to evaluate equation 24 for the width exponent, $b$.

\section{CALIBRATION}

From equations $6,24,25$, and 27 , it is apparent that if any one of the five power-function exponents $(b, f, m, z$, and $y$ of eqs. 1 to 5 ) is known or can be reasonably assumed for channels of specified width-depth ratio, unique solutions for the other four exponents follow. For example, assume that the empirically developed value for $z,-0.25$, for channels of constant particle-size distribution is also appropriate for channels of specified width-depth ratio. From equation $23, d$ for any channel with a width-depth ratio of 30 equals 0.13 ; from equations 17 and 18, values of $j_{1}$ through $j_{6}$, respectively, are $0.84,1.24,0.82,0.10,0.74$, and 0.79 . (Values of $j_{2}$ and $j_{5}$, are required only if the coefficients $a$ and $c$ are calculated by eqs. 17 and 18.) Using equations 25,27 , and 24 as previously described, values of $b, f$, and $y$ are, respectively, $0.59,0.29$, and -0.05 . From equation $6, m$ is 0.12 . Similar computations, all with an assumed $z$-value of -0.25 , yield a $b$-value of 0.53 for channels with a widthdepth ratio of 5.0 and 0.60 for channels with a widthdepth ratio of 50. If an assumed $z$-value of 0 is applied to braided channels with width-depth ratios of 1,000 , the calculated values of $b, f$, and $m$, respectively, are 0.97 , 0.02 , and 0.01 .

The analytical results using a value for $z$ of -0.25 (or 0 for braided channels) are consistent with empirical results for channels of relatively large width-depth ratios, but appear to overestimate $b$ for deep, narrow channels. For the other exponents, field data usually are adequate only to define the exponent for the width-discharge relation. Channel depths generally are more difficult to measure with repeatable precision than are widths, and velocity and roughness data generally are either unavailable or have been estimated. Thus, empirically developed values of $b$ are selected as the means to calibrate the other exponents of the channelgeometry relations.

\section{EMPIRICALLY DEVELOPED RELATIONS}

Several recent studies in the Western United States (Osterkamp, 1980; Hedman and Osterkamp, 1982; Osterkamp and Hedman, 1982) provide empirically developed $b$-values for groups of stable channels with similar bed- and bank-sediment characteristics. The values range from 0.47 for channels formed largely of silt and clay to 0.62 for channels with sandy beds and banks; channels armored with gravel, cobbles, and boulders generally have $b$-values ranging from 0.51 to 0.55. Data from a small group of braided channels in the Sand Hills area of Nebraska yielded a $b$-value of 1.0 (Osterkamp, 1980, p. 193). Because large ranges of mean discharge are represented in each of the channelsediment groups, characteristic width-depth ratios cannot be identified for the various groups. Mean values of width-depth ratio, however, are smallest for the silt-clay channels and increase progressively as the value of $b$ increases. Because the results described above represent conditions of unchanging channel-sediment properties rather than unchanging width-depth ratios in the downstream direction, these results cannot be used directly to calibrate the equations presented here. Like the empirical results for the gradient-discharge exponent, however, these results provide a basis for 
evaluating the reasonableness of any assumed or calculated values of $b$ and $z$.

To construct a curve relating the width exponent, $b$, to width-depth ratio, geometry and discharge data from several hundred gage sites of the western half of the United States (Osterkamp and others, 1982) were divided into 10 groups based on width-depth ratio; 318 channels were represented in groups: (1) $W / D \leq 8.0$, (2) $9.0 \leq W / D \leq 11.0$

$$
\text { (3) } 14.0 \leq W / D \leq 18.0 \text {, }
$$

$18.0<W / D \leq 22.0$

$$
\text { (5) } 22.0<W / D \leq 27.0 \text {, }
$$

$27.0<W / D \leq 33.0$

(7) $36.0 \leq W / D \leq 44.0$,

$45.0 \leq W / D \leq 55.0$,

(9) $56.0 \leq W / D \leq 80.0$, and

$80.0<W / D \leq 14.0$.

Data for each group were plotted on logarithmic coordinates and a power relation was determined graphically using the data representing the narrowest channels relative to discharge (figs. 3 to 12). Although all available data were plotted, most are presumed indicative of channels widened to varying degrees by erosive flow events. The narrowest channels relative to discharge, therefore, are judged most representative of stable, fully adjusted conditions, and it is the data from these channels (except for several that appear to have been measured improperly) that most closely approximate the assumptions previously given. Thus, the linear relations of figures 3 to 12 are envelope curves (power functions), describing the narrowest naturally occurring channels for specified ranges of width-depth ratio. Where data are insufficient to describe with reasonable confidence the slope of a lower envelope relation, the slope is based, in large degree, on statistically developed relations from previous studies (Osterkamp, 1980; Osterkamp and Hedman, 1982).

\section{CALIBRATION RESULTS}

The results of figures 3 through 12 and the data upon which they are based are summarized by the equations listed in table 2 and the graphical comparison of them in figure 13. Comparison of the equations shows a nearly consistent increase of both coefficients and exponents with width-depth ratios.

The $b$ exponents of the various width-discharge power functions (table 2; figs. 3 to 12) were plotted in figure 14 as a function of the mean value of width-depth ratio for each group. The plotted points are used to define a general curve (solid line) indicating the manner in which the $b$ exponent for relatively stable alluvial stream channels varies with width-depth ratio. The solid line is extended as a dotted portion where data (table 2) are inadequate to provide reliable results. Also shown in figure 14 are similar points and a curve (dashed line) developed statistically from the width-discharge relations of Osterkamp and Hedman (1982) for groups of streams with similar channel-sediment characteristics.
In order that these data could be included and generalized in figure 14, mean values of width-depth ratio were determined for each channel-sediment group. Because several of the contrast groups show relatively large ranges of width-depth ratio, the mean values of widthdepth ratio for the sediment groups (crosses, fig. 14) do not necessarily provide an accurate relation with the $b$ exponents. The dashed-line curve nevertheless provides a comparison that supports the solid-line curve used here (fig. 14) through the low to moderate width-depth ratios; the dashed-line curve provides increased accuracy for the higher ratios. The displacement between the two curves probably is caused by the difference in method used to develop them. The solid-line curve is based on data representing only narrow, presumably stable, channel sections; the dashed-line curve is based on all data representing channel-sediment groups, many of which do not approach steady-state conditions.

The solid-line curve given in figure 14 is used as the principal basis of calibration for evaluating equations 24 and 25 because of (1) the similarity between it and the dashed-line curve of figure 14, (2) the general agreement of the $b$-values, taken from figure 14, with numerous other empirical values as well as most theoretically developed values (table 1), and (3) the solid-line curve's general conformity to the theoretical requirement that $b$ approach 1.0 as width-depth ratios become very large. The $b$-exponent then corresponds to any width-depth ratio of the solid-line curve and is assumed accurate; the other four exponents (eqs. 2 to 5 ) are calculated accordingly.

Listed in table 3 for selected width-depth ratios of 5.0 to 1,000 are exponent values (for eqs. 1 to 5) and the $d$ and $j$ values from which they were calculated. The $b$ values, taken directly from the curve of figure 14, are those values corresponding to the selected width-depth ratios. Also listed are values of $j_{2}$ and $j_{5}$ that are necessary to calculate the coefficients of equations 24 and 25. The exponents are given to three significant figures in order to provide consistency, but there is no

TABLE 2.-Power relations of width to discharge developed from field data of channels in the Western United States and grouped by widthdepth ratios

\begin{tabular}{|c|c|c|c|c|}
\hline \multirow[b]{2}{*}{ Group } & \multirow[b]{2}{*}{ Figure No. } & \multicolumn{2}{|c|}{ Width-depth ratios } & \multirow[b]{2}{*}{ Equation } \\
\hline & & Range & Midpoint & \\
\hline- & 3 & $\leq 8.0$ & 7.0 & $W=4.1 Q^{0.48}$ \\
\hline - & 4 & $9.0-11.0$ & 10.0 & $W=4.6 Q^{0.49}$ \\
\hline- & 5 & $14.0-18.0$ & 16.0 & $W=4.8 Q^{0.51}$ \\
\hline 4 & 6 & $>18.0-22.0$ & 20.0 & $W=5.8 Q^{0.54}$ \\
\hline 5 & 7 & $>22.0-27.0$ & 24.5 & $W=5.8 Q^{0.51}$ \\
\hline 6 & 8 & $>27.0-33.0$ & 30.0 & $W=6.4 Q^{0.53}$ \\
\hline $7 \ldots$ & 9 & $36.0-44.0$ & 40.0 & $W=6.6 Q^{0.56}$ \\
\hline 8 & 10 & $45.0-55.0$ & 50.0 & $W=6.9 Q^{0.58}$ \\
\hline 9 & 11 & $56.0-80.0$ & 68.0 & $W=6.0 Q^{0.77}$ \\
\hline 10 & 12 & $>80.0-140$ & 110 & $W=7.1 Q^{0.82}$ \\
\hline
\end{tabular}

[W, channel width in meters; $Q$, mean discharge in cubic meters per second] 


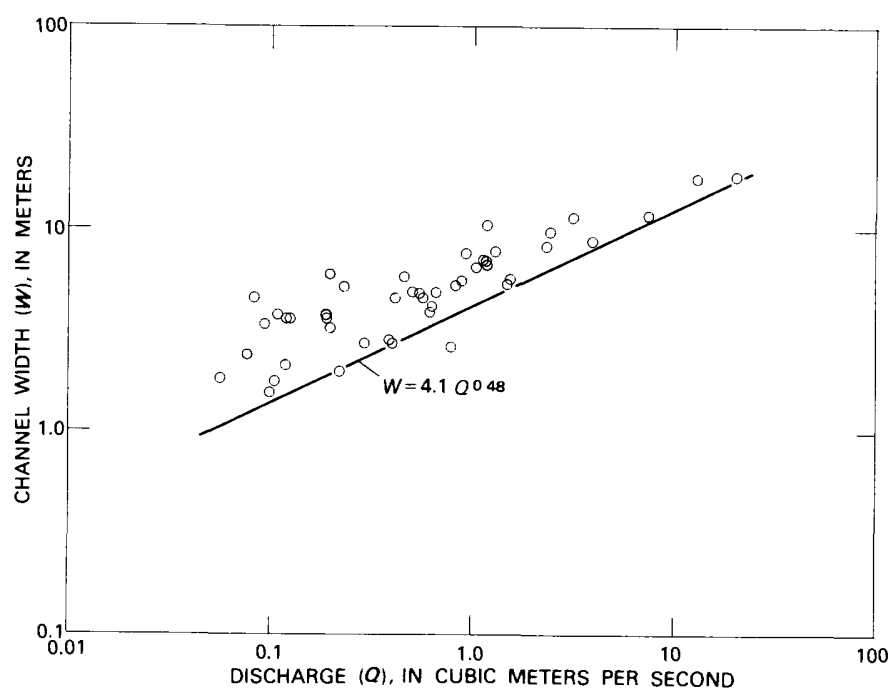

Figure $3 .-W / D \leq 8.0$.

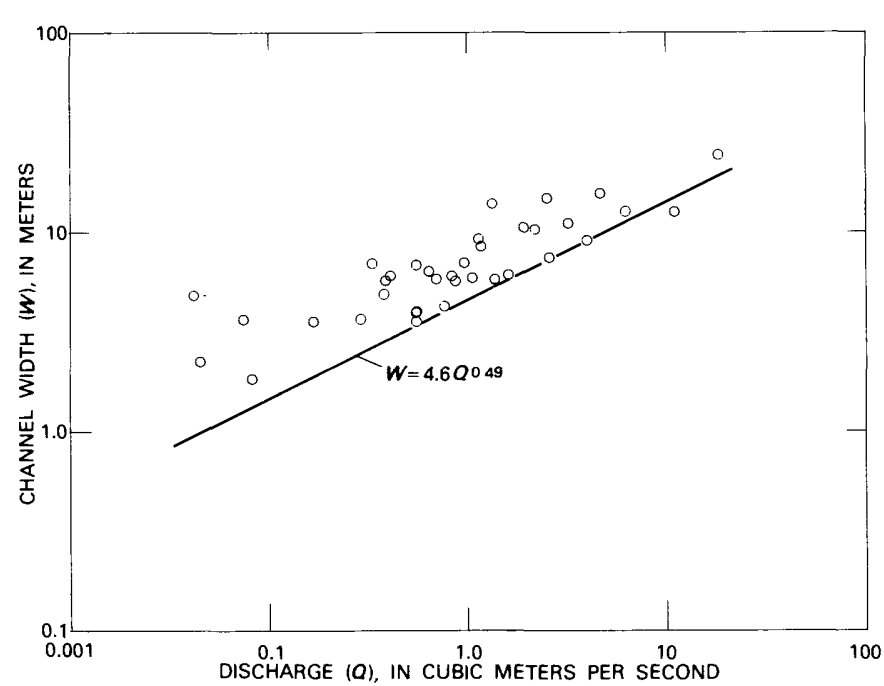

FIGURE 4. $-9.0 \leq W I D \leq 11.0$

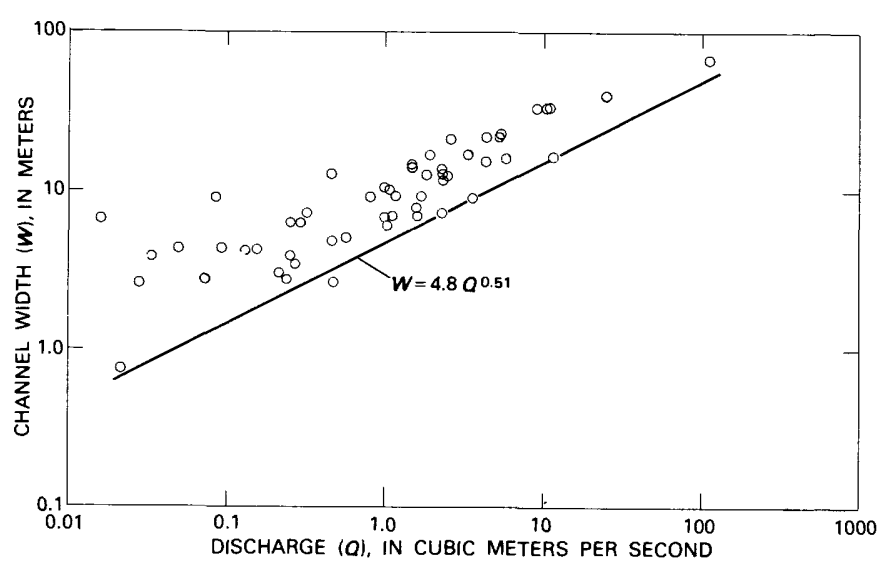

FigURE 5. $-14.0 \leq W / D \leq 18.0$.

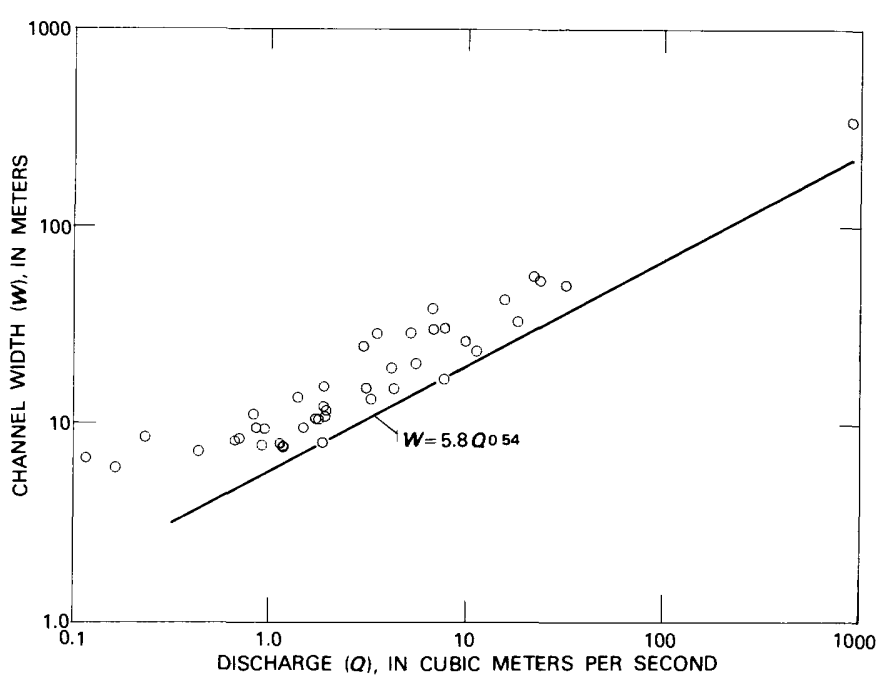

FIGURE 6. $-18.0 \leq W / D \leq 22.0$.

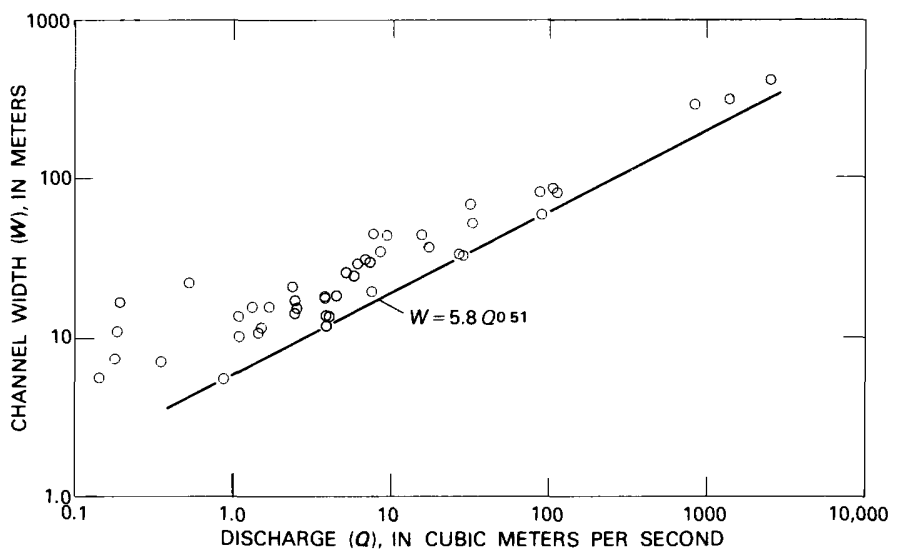

FiguRE 7. $-22.0 \leq W / D \leq 27.0$.

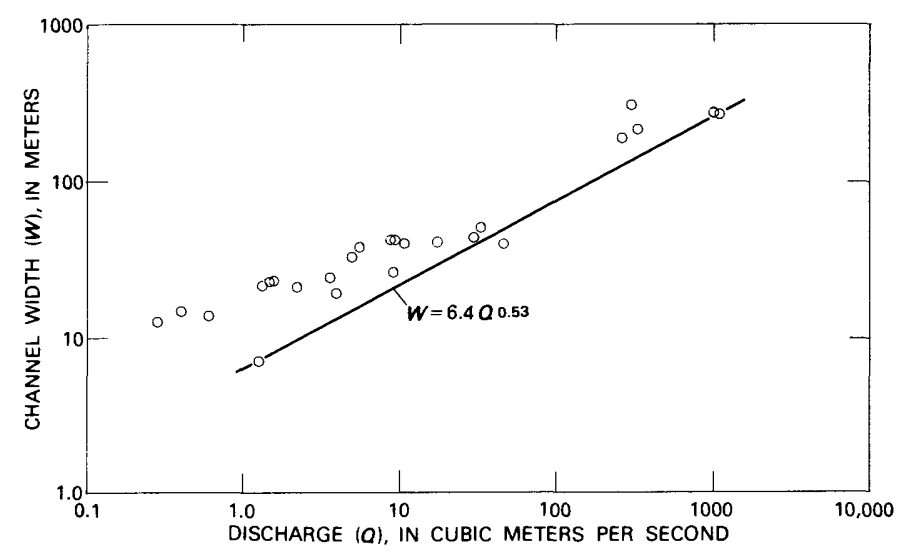

Figure 8. $-27.0 \leq W / D \leq 33.0$.

FIGURES 3-12.-Width-discharge data and power relations for groups of channels. The relation line is fitted to the 

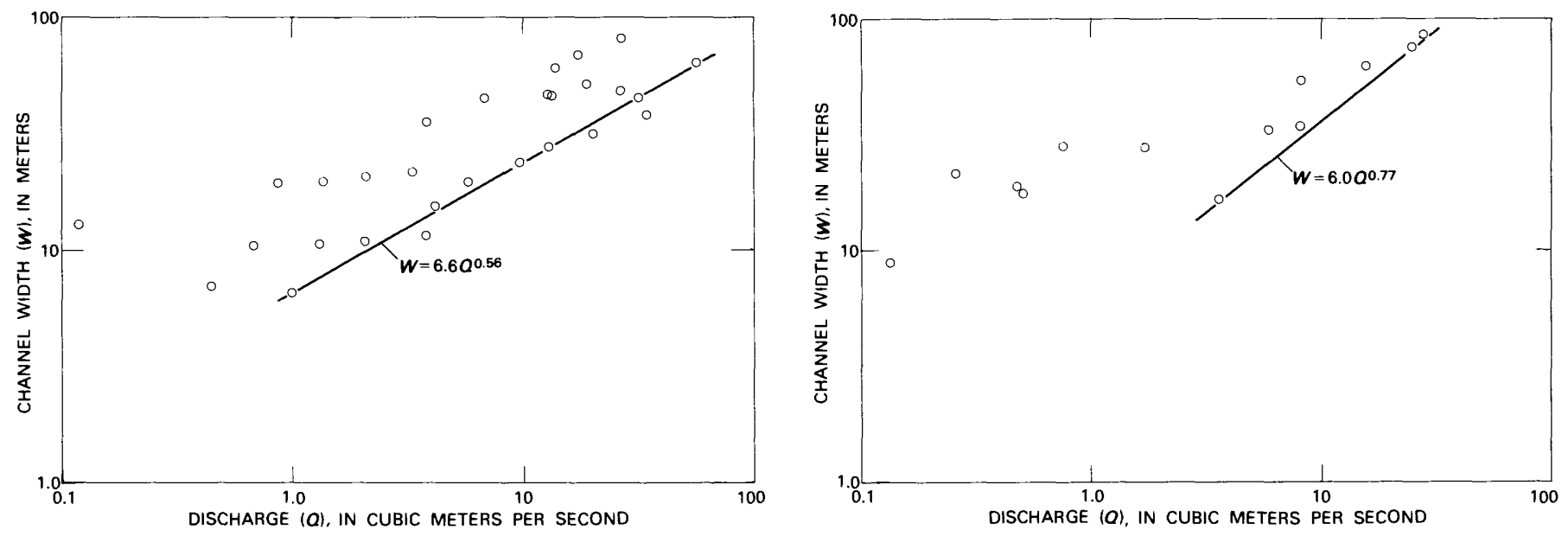

FIGURE 9. $-36.0 \leq W / D \leq 44.0$.

FIGURE 11. $-56.0 \leq W / D \leq 80.0$.
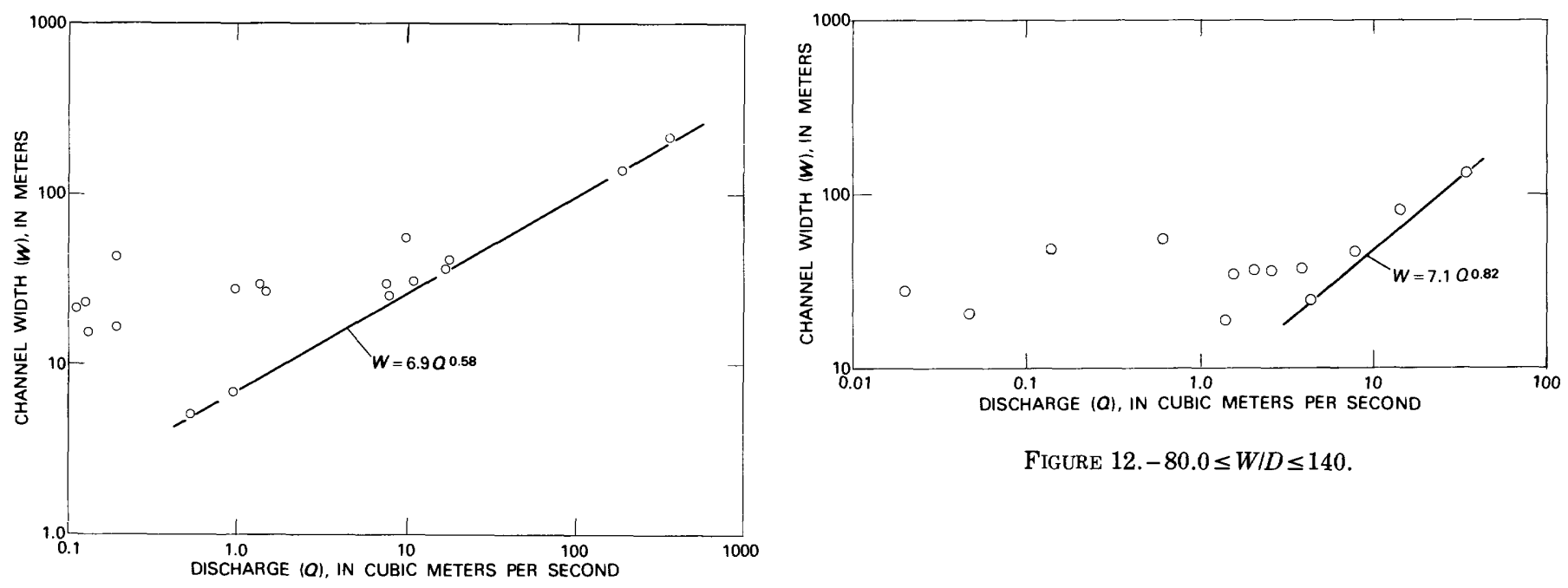

Figure 12. $-80.0 \leq W / D \leq 140$.

FiguRe 10. $-45.0 \leq W / D \leq 55.0$.

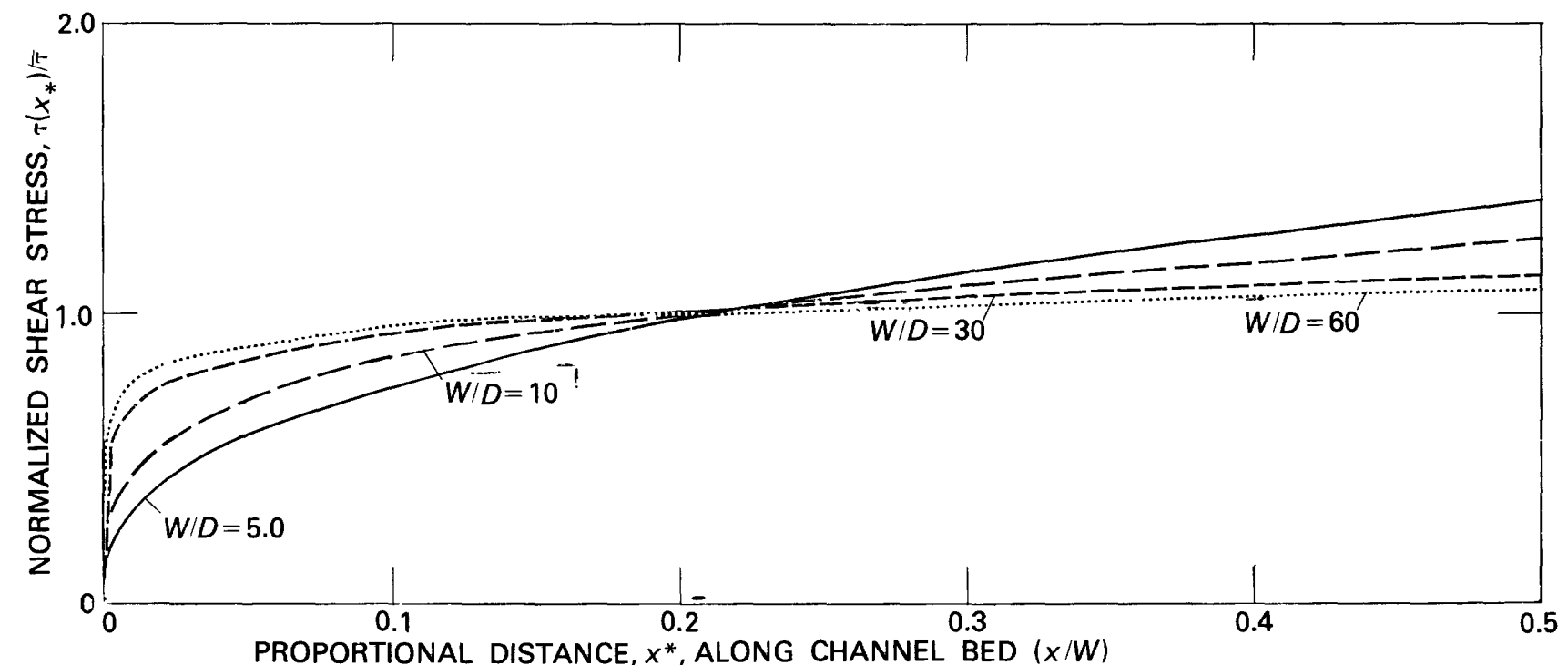

data points representing the narrowest reliable width measurements, relative to mean discharge, that are available. 
implication intended that these results are accurate to three significant figures. The exponent data, as functions of width-depth ratio, are presented graphically in figure 15 and show the manner in which each of the different exponents changes relative to the other four.

The value of $z$ can be considered a measure of the concavity of the channel profile to which it is applied; the largest negative value of $z$ is associated with the most concave profile and a $z$-value of 0 indicates a linear profile. The previously described empirical results suggest a nearly fixed value for $z,-0.25$ for channels of constant channel-sediment characteristics. Those results are in general support of the larger negative values calculated here for channels of specified width-depth ratio. In both cases (specified width-depth ratio and specified channelsediment characteristics), the exponent shows little or no change for most channels - those with width-depth ratios ranging from 12 to 40 . Larger negative values of $z$ for channels of fixed width-depth ratio than for those of constant channel-sediment characteristics are consistent with numerous field observations. As mean discharge increases in the downstream direction, stream channels have a general tendency to increase in width-depth ratio and bed and banks content of finegrained, cohesive sediment. (See data of Osterkamp and others, 1982; Osterkamp and Hedman, 1982.) Without a downstream increase of silt-clay content, width-depth ratios necessarily must increase at a faster rate than is typical for alluvial stream channels. In figure 15 , and thus in equations 24 and 25 , increasing width-depth ratios are accompanied by decreasing negative values of $z$. Thus, the condition of constant particle sizes in the downstream direction, which generally signifies increasing width-depth ratios, also is suggestive of a less concave profile and lower negative values of $z$ than is the condition of specified width-depth ratio. The absolute values of $z$ calculated here (table 3 and fig. 15) are mostly about 30 percent larger than the value of -0.25 indicated by field studies (Lane, 1957; Osterkamp, 1978).
The general agreement of the -0.25 value with the calculated $z$-values given here (table 3 ) provides independent qualitative confirmation of the calibration based on the assumed $b$ values.

\section{SENSITIVITY TO ASSUMED VALUES OF $Z$}

Empirically developed values of $b$ are more accurately known than those of $z$, largely because channel widths change at a much greater rate with mean discharge than do channel gradients. Therefore, if extensive gradientdischarge field data for channels of limited ranges of width-depth ratio were available, they probably would not permit as accurate a calibration as do the widthdischarge data. If it is accepted that the $z$-values for stable channels of specified width-depth ratio should be of moderately larger negative value than those values identified for channels of constant sediment characteristics $(-0.25)$, then the calibration given here (table 3 and fig. 15), based on the empirically developed $b$-values (figs. 3-12), appears to be reasonably accurate.

Figure 16 illustrates the manner in which $b, f, m$, and $y$ change with variations in the value of $z$ for width-depth ratios of 10 and 30 . The curves of figure 16 , which were developed by use of equations $25,27,24$, and 6 , and a variety of assumed $z$-values, therefore represent the sensitivity of the other exponents to changes in $z$ for width-depth ratios of a range of typical well-formed alluvial stream channels. The curves show that if the absolute values of $z$ were less than -0.25 , the resulting $b$-values would be larger than the range of 0.45 to 0.55 commonly indicated by empirical studies as well as by several theoretical approaches (table 1). If $z$ is of greater absolute value than -0.43 , any value of $b$ for width is necessarily smaller than that of $f$ for depth; empirical studies and theoretical approaches have also suggested that $b$ normally is of greater value than $f$ for natural alluvial stream channels. Figure 16 suggests, therefore, that for a condition of constant width-depth ratio in the

TABLE 3.-Calculated and assumed values of $\mathrm{d}, \mathrm{j}_{1}$ through $\mathrm{j}_{6}, \mathrm{~b}, \mathrm{f}, \mathrm{m}, \mathrm{z}$, and y for width-depth ratios of 5 to 1,000

\begin{tabular}{|c|c|c|c|c|c|c|c|c|c|c|c|c|}
\hline $\begin{array}{l}\text { Width-depth } \\
\text { ratio }(W / D)^{1}\end{array}$ & $\begin{array}{c}d \\
(W / D)^{-\infty} \text { so }\end{array}$ & $\begin{array}{c}\begin{array}{c}j_{1} \\
3 d+3\end{array} \\
8 d+3\end{array}$ & $\begin{array}{c}\frac{j_{2}}{5} \\
8 d+3\end{array}$ & $\frac{\begin{array}{c}j_{3} \\
-3 d\end{array}}{16 d+6}$ & $\begin{array}{c}j_{4} \\
\frac{3 d}{8 d+3}\end{array}$ & $\begin{array}{c}j_{\mathrm{s}} \\
\frac{3}{8 d+3}\end{array}$ & $\begin{array}{c}\begin{array}{c}j_{6} \\
\frac{3 d+6}{16 d+6}\end{array} \\
16 d+6\end{array}$ & $b$ & $f$ & $m$ & $z$ & $y$ \\
\hline 5.0 & 0.381 & 0.685 & 0.827 & 0.484 & 0.189 & 0.496 & 0.591 & 0.446 & 0.413 & 0.141 & -0.400 & -0.069 \\
\hline 7.0 & .311 & .717 & .911 & .553 & .170 & .547 & .632 & .476 & .386 & .138 & -.360 & -.064 \\
\hline 10 & .251 & .749 & .998 & .624 & .150 & .599 & .674 & .500 & .365 & .135 & -.330 & -.059 \\
\hline 12 & .225 & .766 & 1.041 & .659 & .141 & .625 & .695 & .510 & .355 & .135 & -.320 & -.059 \\
\hline 16 & .189 & .791 & 1.108 & .713 & .126 & .665 & .728 & .516 & .351 & .133 & -.320 & -.059 \\
\hline 20 & .166 & .808 & 1.155 & .751 & .115 & .693 & .751 & .521 & .349 & .130 & -.320 & -.059 \\
\hline 30 & .130 & .839 & 1.238 & .818 & .097 & .743 & .791 & .529 & .347 & .124 & -.320 & -.056 \\
\hline 40 & .109 & .859 & 1.291 & .862 & .084 & .775 & .817 & .554 & .325 & .121 & -.300 & -.054 \\
\hline 50 & .096 & .873 & 1.327 & .891 & .076 & .796 & .834 & .616 & .276 & .108 & -.240 & -.048 \\
\hline 100 & .063 & .910 & 1.427 & .972 & .054 & .856 & .883 & .891 & .058 & .051 & -.010 & -.010 \\
\hline 1,000 & .016 & .974 & 1.598 & 1.111 & .015 & .959 & .967 & .974 & .015 & .021 & 0 & -.001 \\
\hline
\end{tabular}

1 For width-depth ratios of 5.0 through 100 , values of $z$ were assigned to yield an assumed $b$ value conforming with that shown in figure 14; for a width-depth ratio of 1,000 , a $z$ value of 0 , indicative of a linear channel profile, was assumed. 


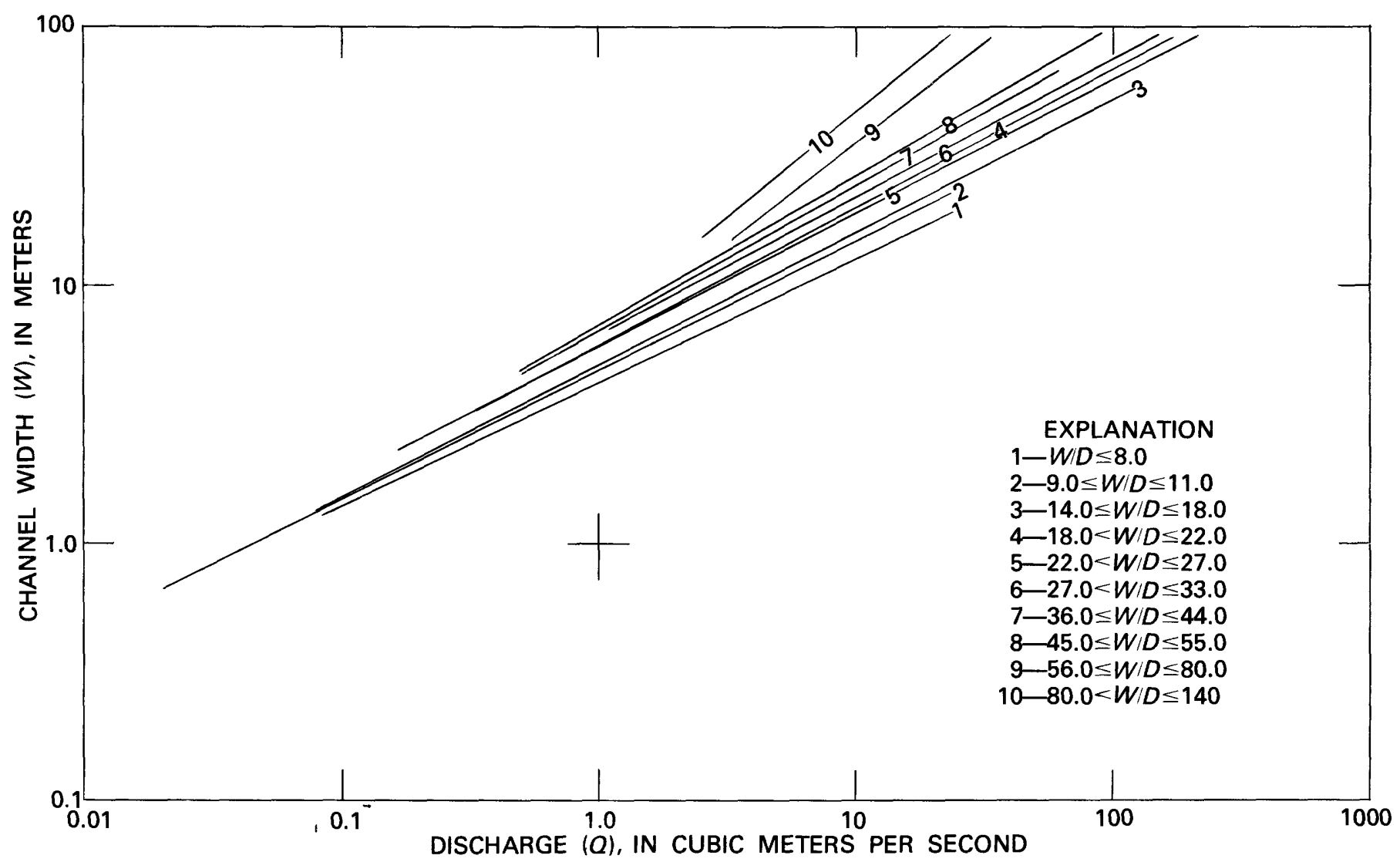

FIGURE 13. - Width-discharge relations for groups of stream channels with similar width-depth ratios $(W / D)$.

downstream direction, the z-exponent (eq. 4) normally varies between -0.25 and -0.40 . However, lower negative values occur for very wide stream channels relative to discharge (table 2 ).

Figure 16 also illustrates that the $b, f, m$, and $y$ exponents show increasing sensitivity to changes in $z$ with increasing width-depth ratio. The $f$ and $y$ exponents, for depth and bed roughness, show the greatest rates of change with variation of $z$, but the absolute effect on any $y$-value by changes of $z$ is minor owing to the small magnitude of $y$. The width exponent, $b$, shows limited change with $z$ values of smaller magnitude than -0.4 ; this suggests that, as pointed out earlier, of the five exponents (eqs. 1 to 5), $b$ is well-suited to be the basis for calibrating equations 24 and 25 .

\section{APPLICATIONS}

Equations 24 and 25, which are semitheoretical, and the equations of table 2 , which provide both empirical support and a means of calibrating equations 24 and 25 , demonstrate that geometry-discharge relations of alluvial channels cannot be readily generalized from single power equations. The recognition that the coeffi- cients and exponents of equations 1 to 5 are variable, dependent at least in part on the mobile sediment supply of a channel system, leads to various assumptions and conclusions regarding fluvial processes. Several of these assumptions and conclusions are discussed in the following section.

\section{CHANNEL ADJUSTMENT}

Basic to the derivation leading to equations 24 and 25 is that the mean shear stress in a channel is a function of the instantaneous water-sediment discharge:

$$
\bar{\tau}=F\left(Q_{i}\right) .
$$

Among the assumptions of the derivation is the occurrence of approximate channel adjustment to the meandischarge conditions of the water-sediment mixture. As discharge in a channel section increases, the erosiveness (owing to greater velocities and turbulence) generally increases also. Thus, the assumption of equilibrium requires relatively uniform discharge conditions in which the erosive (shear) stresses at the channel perimeter are in balance through time with the gravitational and cohesive forces resisting movement of channel sediment. 


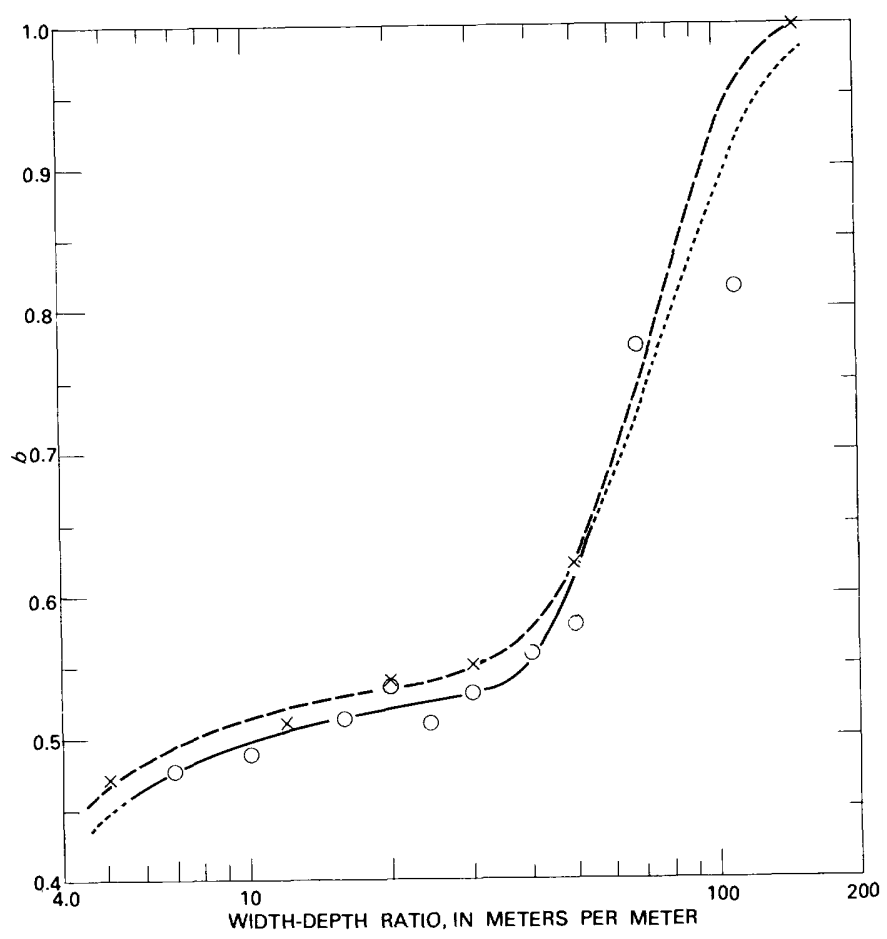

FIGURE 14.-Variation of the width exponent, $b$, with width-depth ratio. Circles and solid line represent data points and resulting curve (dotted where poorly defined) for channels grouped by similar widthdepth ratios (table 2); crosses and dashed line represent data points and resulting curve for channels grouped by sediment characteristics.

The geometry and other channel characteristics, such as bed configuration, the median particle size of bed material $\left(d_{50}\right)$, and the silt-clay content of the channel material $(S C)$ are determined largely by the discharge of water and sediment. From equation 28, therefore,

$$
\left[W, D, G, n, d_{50}, S C, \ldots\right]=\mathrm{F}\left(Q_{i}\right) \text {; }
$$

for self-formed alluvial channels, all the bracketed variables of equation 29 are associated with the distribution of shear stresses. The derivation resulting in equations 24 and 25 is based not only on relations in equations 28 and 29 , but also on the assumption that $Q_{i}$ is relatively uniform through time. Thus, the mean shear stress in the channel, $\bar{\tau}$, also is assumed to have little variation through time.

Most natural alluvial stream channels do not have nearly constant discharge, but show variations of at least several orders of magnitude. A channel that is widened by the excessive shear stresses of an erosive flood, therefore, is not adjusted to the conditions of mean discharge following the flood. Generally, the channel requires an extended period of normal flow conditions and shear stresses before accretion and deposition of fine sediment are sufficient to affect channel narrowing and an essentially adjusted geometry. If the sedi-

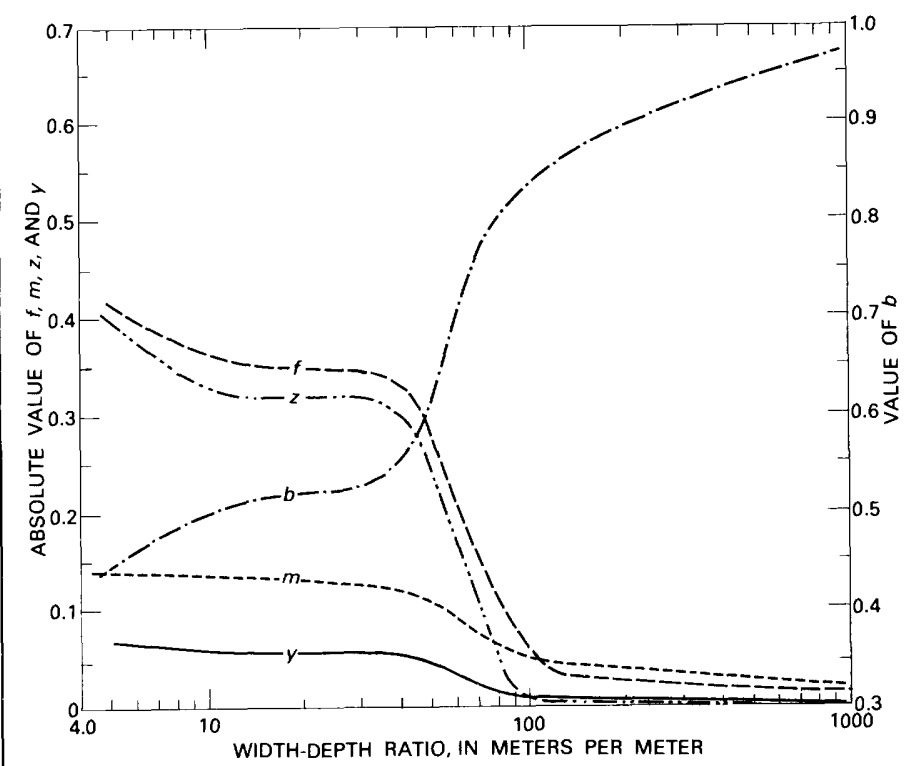

FIGURE 15. - Change of $b, f, m, z$, and $y$ with change of width-depth ratio. Values of $b, f$, and $m$ are positive; values of $z$ and $y$ are negative.

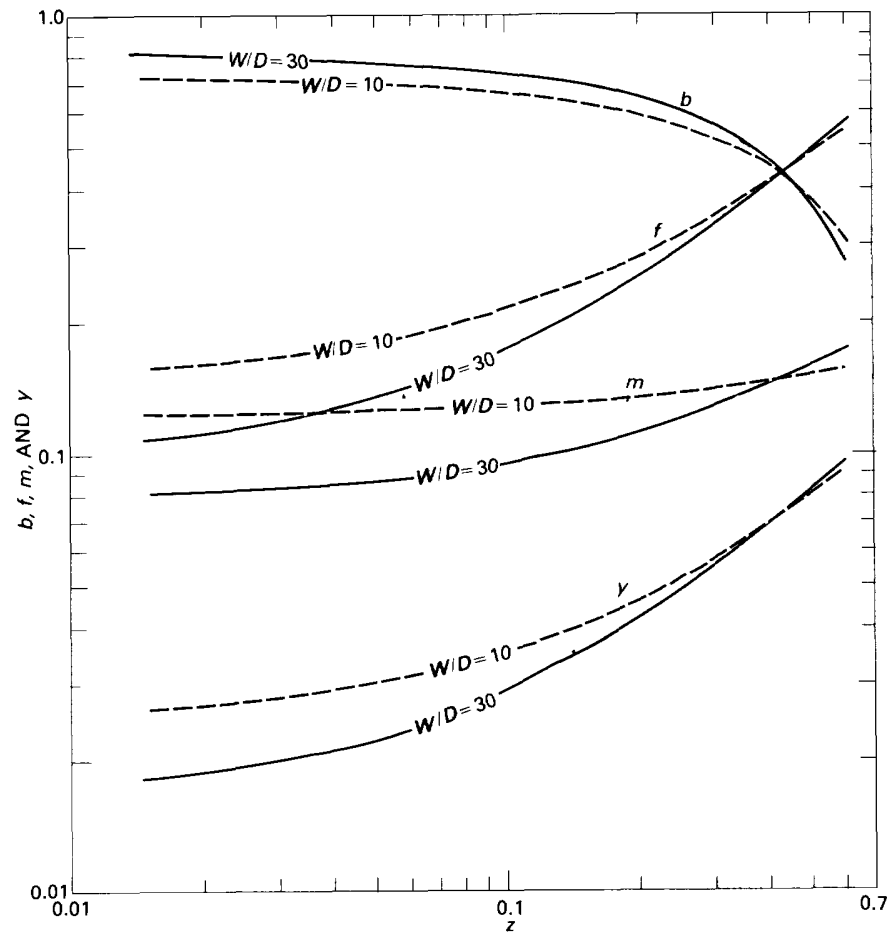

FIGURE 16. -Change of $b, f, m$, and $y$ with variation in values of $z$ for selected width-depth ratios $(W / D)$.

ment available for fluvial transport is principally of sand sizes, the rate of narrowing may be slow owing to a lack of fine cohesive material to form a stable channel section. If abundant fine sediment is available to a stream channel, narrowing toward a geometry approaching equilibrium following an erosive flood may be relatively 


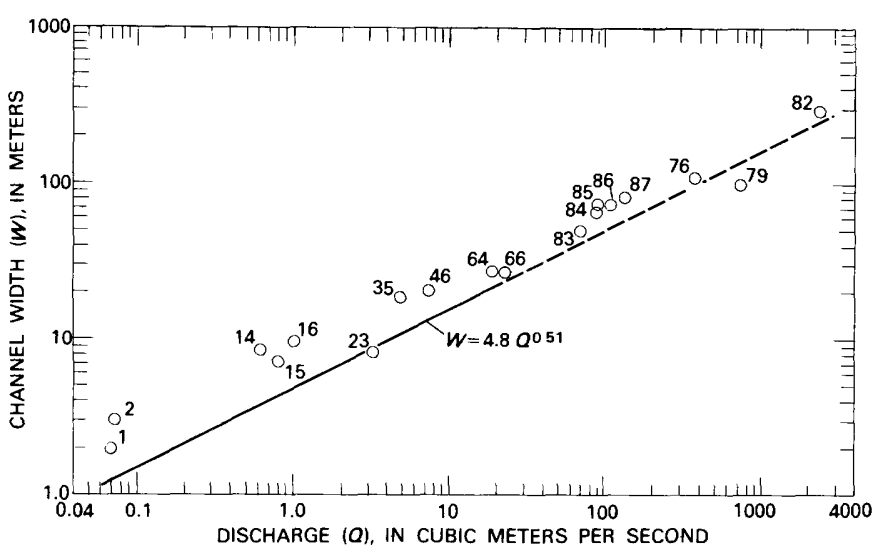

FIGURE 17. - Relation of width to discharge for $14.0 \leq W / D \leq 18.0$.

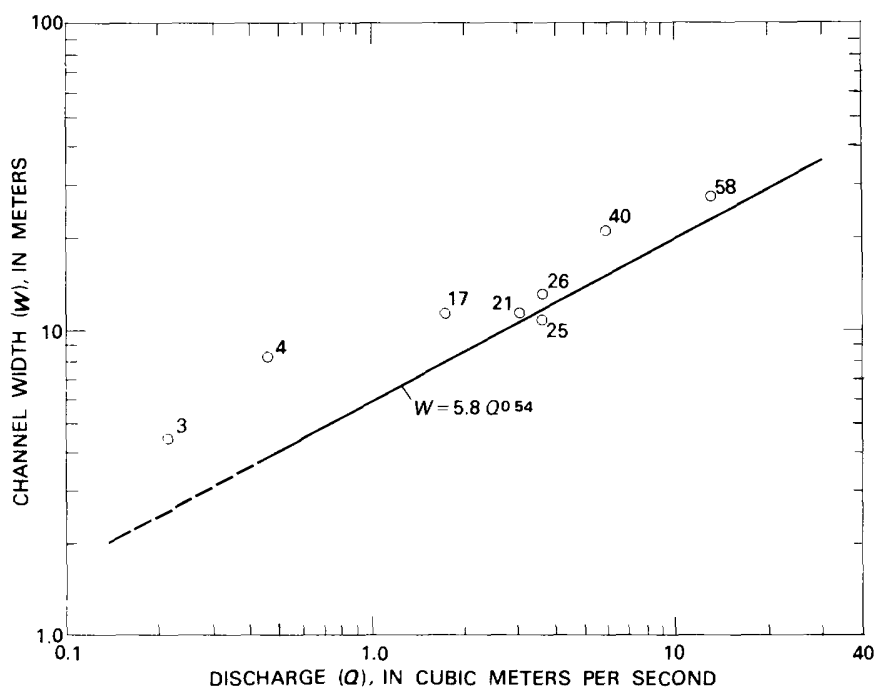

FIgURE 18. - Relation of width to discharge for $18.0 \leq W / D \leq 22.0$.

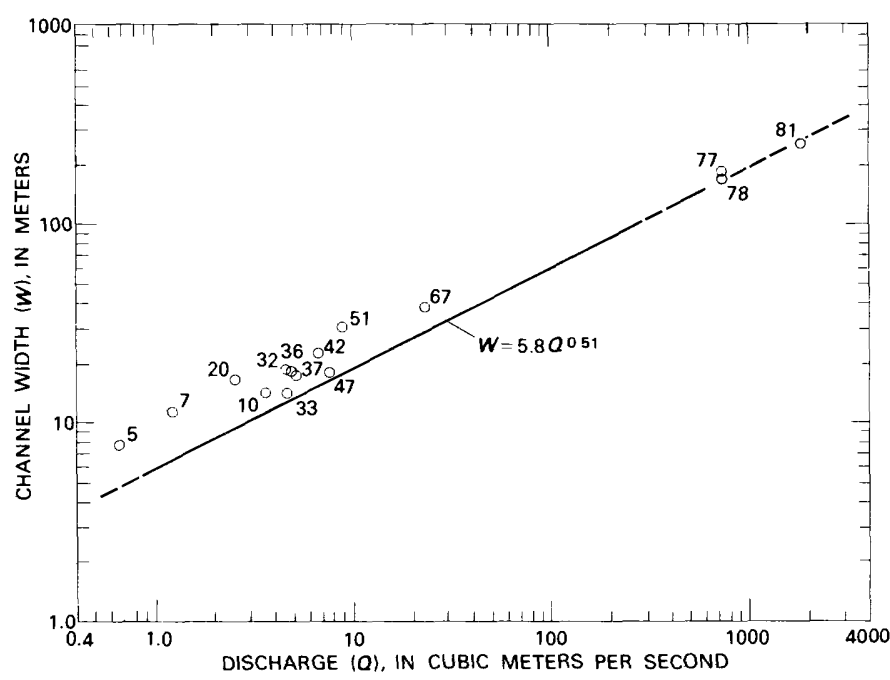

FIGURE 19.-Relation of width to discharge for $22.0<W / D \leq 27.0$.

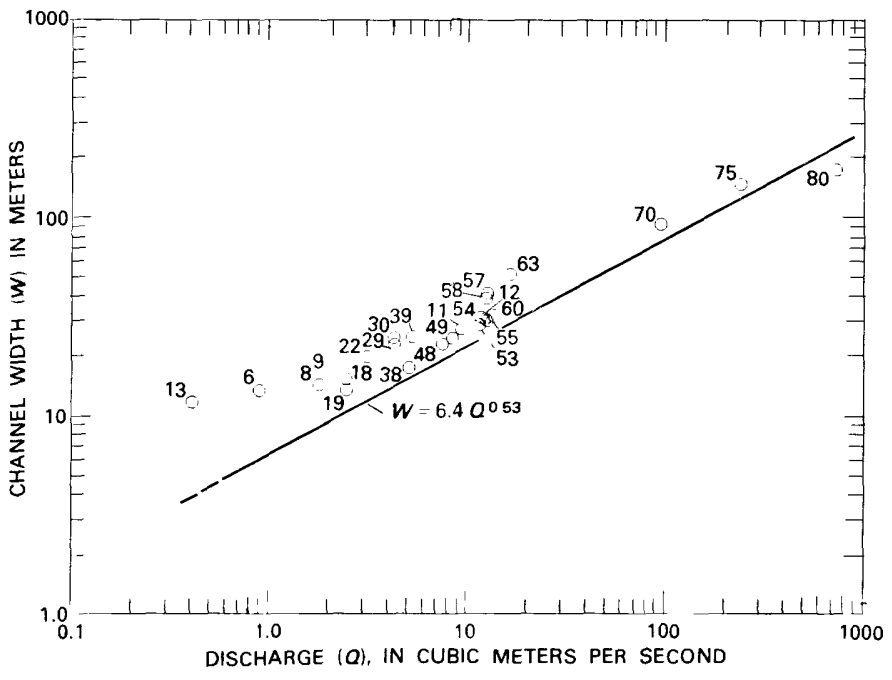

FIGURE 20.-Relation of width to discharge for $27.0<W / D \leq 33.0$.

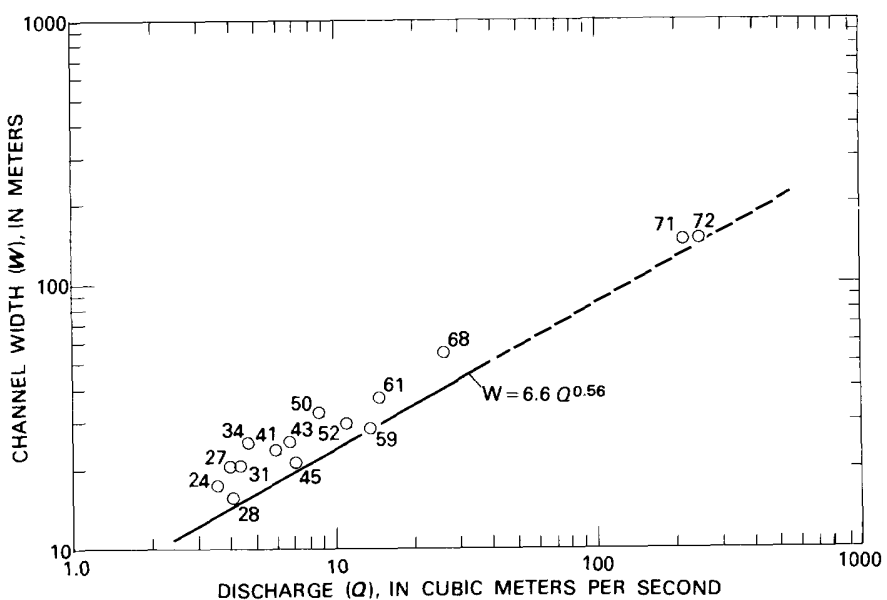

FIGURE 21. - Relation of width to discharge for $36.0 \leq W / D \leq 44.0$.

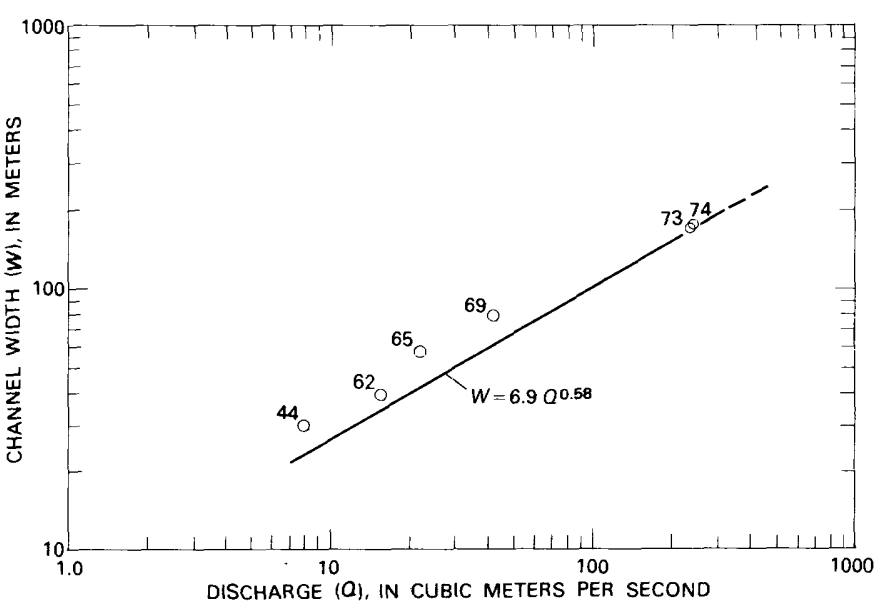

FIGURE 22.-Relation of width to discharge for $45.0 \leq W / D \leq 55.0$.

FIGURES 17-22. - Relations of width to discharge for channels of the Western United States. Numbers refer to comparative data in table 4 from the United States-in Ohio and southern Missouri-New Guinea, and Australia; dashed segments are extrapolations of the relation lines beyond the limits defined by the Western United States data. 
TABLE 4. - Geometry-discharge data from natural stream channels with stable discharge

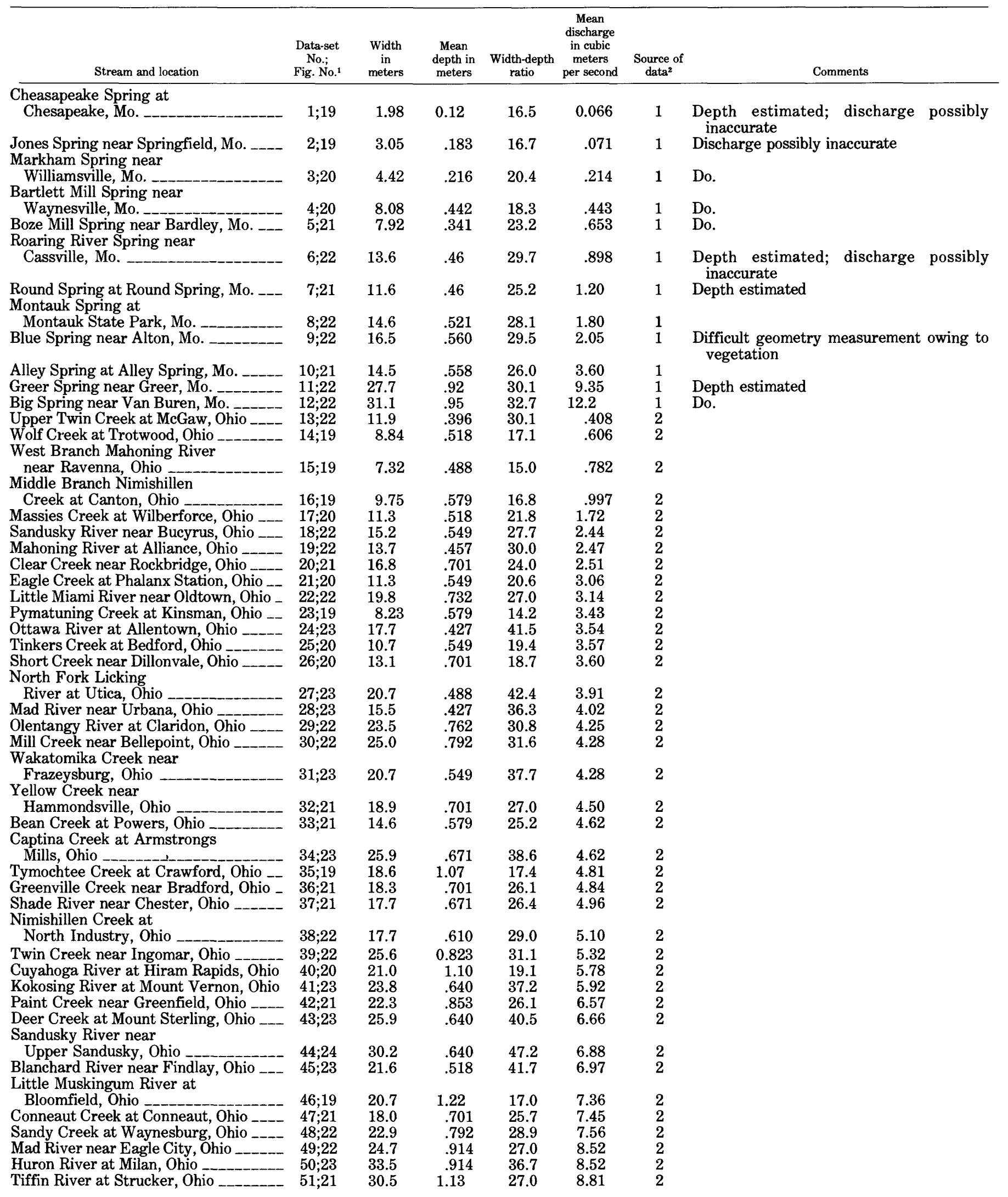


TABLE 4.-Geometry-discharge data from natural stream channels with stable discharge-Continued

\begin{tabular}{|c|c|c|c|c|c|c|c|}
\hline Stream and location & $\begin{array}{l}\text { Data-set } \\
\text { No.; } \\
\text { Fig. No. }{ }^{1}\end{array}$ & $\begin{array}{l}\text { Width } \\
\text { in } \\
\text { meters }\end{array}$ & $\begin{array}{l}\text { Mean } \\
\text { depth in } \\
\text { meters }\end{array}$ & $\begin{array}{l}\text { Width-depth } \\
\text { ratio }\end{array}$ & $\begin{array}{c}\text { Mean } \\
\text { discharge } \\
\text { in cubic } \\
\text { meters } \\
\text { per second }\end{array}$ & $\begin{array}{l}\text { Source of } \\
\text { data }^{2}\end{array}$ & Comments \\
\hline Little Miami River near & & & & & & & \\
\hline Spring Valley, Ohio & $52 ; 23$ & 30.2 & .732 & 41.3 & 10.9 & 2 & \\
\hline Killbuck Creek at Killbuck, Ohio & $53 ; 22$ & 29.0 & .945 & 30.7 & 11.5 & 2 & \\
\hline Cuyahoga River at Old Portage, Ohio & $54 ; 22$ & 31.1 & 1.01 & 30.8 & 11.9 & 2 & \\
\hline Tuscarawas River at Missillon, Ohio & $55 ; 22$ & 29.9 & 1.07 & 27.9 & 12.3 & 2 & \\
\hline Big Darby Creek at Darbyville, Ohio & $56 ; 22$ & 39.0 & 1.31 & 29.8 & 12.7 & 2 & \\
\hline Scioto River near Prospect, Ohio & $57 ; 22$ & 40.8 & 1.49 & 27.4 & 12.8 & 2 & \\
\hline Hocking River at Enterprise, Ohio & $58 ; 20$ & 27.7 & 1.34 & 20.7 & 12.9 & $\overline{2}$ & \\
\hline Great Miami River at Sidney, Ohio & $59 ; 23$ & 29.0 & .671 & 43.2 & 13.4 & 2 & \\
\hline Mad River near Springfield, Ohio & $60 ; 22$ & 32.3 & 1.19 & 27.1 & 13.7 & 2 & \\
\hline Little Beaver Creek near & & & & & & & \\
\hline East Liverpool, Ohio _... & $61 ; 23$ & 38.4 & 1.01 & 38.0 & 14.7 & 2 & \\
\hline East Fork Little Miami River at & & & & & & & \\
\hline Perintown, Ohio & $62 ; 24$ & 39.3 & .792 & 49.6 & 15.6 & 2 & \\
\hline Licking River near Newark, Ohio & $63 ; 22$ & 51.5 & 1.71 & 30.1 & 16.4 & 2 & \\
\hline Raccoon Creek at Adamsville, Ohio & $64 ; 19$ & 27.7 & 1.62 & 17.1 & 18.5 & $\overline{2}$ & \\
\hline Scioto River near Dublin, Ohio & $65 ; 24$ & 57.0 & 1.19 & 47.9 & 22.2 & $\overline{2}$ & Below O'Shaughnessy Dam, regulated \\
\hline Cuyahoga River at Independence, Ohio & $66 ; 19$ & 27.4 & 1.52 & 18.0 & 22.7 & 2 & \\
\hline Paint Creek near Bourneville, Ohio & $67 ; 21$ & 39.0 & 1.55 & 25.2 & 22.7 & $\overline{2}$ & \\
\hline Mohican River at Greer, Ohio & $68 ; 23$ & 55.5 & 1.31 & 42.4 & 25.5 & 2 & \\
\hline Walhonding River near Nellie, Ohin & $69 ; 24$ & 79.6 & 1.65 & 48.2 & 41.6 & 2 & Below Mohawk Dam, regulated \\
\hline Scioto River at Chillicothe, Ohio & $70 ; 22$ & 92.0 & 2.80 & 32.9 & 96.5 & 2 & \\
\hline Muskingum River at & & & & & & & \\
\hline McConnelsville, Ohio & $71 ; 23$ & 151 & 3.84 & 39.3 & 211 & 2 & \\
\hline $\begin{array}{l}\text { Ok Tedi at Ningerum, New Guinea, } \\
\text { sec. } 1\end{array}$ & $72 ; 23$ & 150 & 3.5 & 42.9 & 240 & 3 & Gage site \\
\hline $\begin{array}{l}\text { Ok Tedi at Ningerum, New Guinea, } \\
\text { sec. } 2\end{array}$ & $73 ; 24$ & 170 & 3.5 & 48.6 & 240 & 3 & $1030 \mathrm{~m}$ upstream of gage \\
\hline Ok Tedi at Ningerum, New Guinea, & $74 ; 24$ & 175 & 3.5 & 50.0 & 240 & 3 & $2250 \mathrm{~m}$ upstream of gage \\
\hline $\begin{array}{l}\text { Ok Tedi at Ningerum, New Guinea, } \\
\text { sec. } 4\end{array}$ & $75 ; 22$ & 150 & 5.0 & 30.0 & 240 & 3 & $3310 \mathrm{~m}$ upstream of gage \\
\hline Aure River near mouth, New Guinea -- & $76 ; 19$ & 110 & 7.5 & 14.7 & 370 & 3 & \\
\hline $\begin{array}{l}\text { Alice River at Kokonda, } \\
\text { New Guinea, sec. } 1\end{array}$ & 77.01 & 185 & 70 & $2 c 1$ & & & $1190 \mathrm{~m}$ dourmatronm of $\mathrm{mme}$ \\
\hline Alice River at Kokonda, & $77 ; 21$ & 185 & 7.0 & 26.4 & 726 & 3 & $4190 \mathrm{~m}$ downstream of gage \\
\hline New Guinea, sec. 2 - & $78 ; 21$ & 170 & 7.5 & 22.7 & 726 & 3 & $2100 \mathrm{~m}$ downstream of gage \\
\hline $\begin{array}{l}\text { Alice River at Kokonda, } \\
\text { New Guinea, sec. } 3\end{array}$ & $79 \cdot 19$ & & & & & & \\
\hline $\begin{array}{l}\text { New Gumea, sec. } 3 \text { - } \\
\text { Alice River at Kokonda, }\end{array}$ & $79 ; 19$ & 100 & 6.0 & 16.7 & 726 & 3 & Gage site \\
\hline New Guinea, sec. 4 & $80 ; 22$ & 175 & 6.0 & 29.2 & 726 & 3 & $2460 \mathrm{~m}$ upstream of gage \\
\hline Fly River at Kuambit, New Guinea & $81 ; 21$ & 260 & 9.9 & 26.3 & 1780 & 3 & \\
\hline $\begin{array}{l}\text { Purari River below Wabo Dam site, } \\
\text { New Guinea }\end{array}$ & $82 ; 19$ & 250 & 14.3 & 17.52 & 2360 & 3 & $\begin{array}{l}\text { Width average of three sections; depth } \\
\text { estimated }\end{array}$ \\
\hline $\begin{array}{l}\text { Murrumbidgee River near } \\
\text { Maude, Australia }\end{array}$ & $83 ; 19$ & 50.3 & 3.6 & 14.0 & 68.5 & 4 & Depth estimated \\
\hline Murrumbidgee River near Darlington & & & & & & & \\
\hline Point, Australia & $84 ; 19$ & 67.1 & 4.0 & 16.7 & 86.6 & 4 & Do. \\
\hline $\begin{array}{l}\text { Murrumbidgee River near } \\
\text { Hay, Australia }\end{array}$ & & & & & & & \\
\hline $\begin{array}{l}\text { Hay, Australia } \\
\text { Murrumbidgee River near }\end{array}$ & $85 ; 19$ & 74.7 & 5.3 & 14.1 & 88.5 & 4 & Do. \\
\hline $\begin{array}{l}\text { Murrumbidgee River near } \\
\text { Narrandera, Australia }\end{array}$ & $86: 19$ & 75.0 & 45 & 16.7 & 104 & 4 & Do. \\
\hline Murrumbidgee River near & & 10.0 & 4.0 & 10.6 & & & \\
\hline Wagga Wagga, Australia & $87 ; 19$ & 83.2 & 5.0 & 16.6 & 130 & 4 & Do. \\
\hline
\end{tabular}

1 First number is data number shown on the appropriate figure (graph), which is given by the second number 2.

2 1, Field investigations, W. R. Osterkamp; 2, E. E. Webber, written commun. 1981; Webber and Roberts, 1981; 3, Pickup (1977) and Pickup and others (1979); 4, Schumm (1968).

rapid-within a few years if erosive floods do not occur in that period (Osterkamp and Harrold, 1982).

\section{WIDTH-DISCHARGE DATA FROM STABLE NATURAL CHANNELS}

Because hydrologic conditions of the Western United States may be generally conducive to wide and poorly adjusted channel conditions, the relation lines of figures
3 to 12 were tested further using data from natural channels with relatively stable discharge (channels with low flood peaks relative to mean discharge). These data include widths, depths, and mean discharges from (1) spring-effluent channels of southern Missouri, (2) various-sized streams of Ohio (Webber and Roberts, 1981; E. E. Webber, written commun., 1981), (3) large streams of southwestern New Guinea, an area of tropical rainforest (Pickup, 1977; Pickup, and others, 
1979), and (4) five sites along the Murrumbidgee River in New South Wales, Australia (Schumm, 1968). Comparisons of these data with the relations developed from those of the Western United States for width-depth ratios of 14 to 55 are given in figures 17 through 22 . The data are listed in table 4. Data are insufficient for comparisons with higher or lower width-depth ratios.

The slopes (power-function exponents) of the comparison lines provided in figures 17 through 22 are those given in table 2 and figures 5 through 10 . The calculated exponents of table 3 were not used in figures 17 through 22 because the appropriate coefficients (intercepts) necessary to plot the power functions could not be calculated. The error introduced by this approximation, however, is probably small relative to the possible error inherent in the calibration technique. The measurement techniques used to collect the width and depth data of table 4 were consistent with the methods used for the Western United States data. Most of the mean discharges listed were based on streamflow records from gage sites at or near the measurement sites; the remainder were estimated using gage records from upstream or downstream sites.

Presumably because the banks are stabilized by large fractions of silt and clay sediment sizes (G. Pickup, written commun., 1981), the rivers of New Guinea conform well to the relations of inferred equilibrium (figs. 17 to 22). The spring data from southern Missouri represent channels with relatively steady discharges. The springs transport almost no suspended sediment from which cohesive banks can form; but most of the spring channels are formed of sandy to gravelly material derived from the flood-plain alluvium of the rivers into which the springs flow. The lack of cohesive sediment is inferred to account for the slightly greater-than-predicted widths of equilibrium (figs. 19-22).

Within the limitations previously defined, equations 24 and 25 indicate that for a specified discharge and width-depth ratio, only one set of conditions representing complete channel adjustment is possible. The data of table 4 are presented partly to support the power functions of figures 3 through 12 and partly to emphasize the unique values of the channel variables thereby defined. It is only the streams with sufficient suspended sediment to form and maintain stable, cohesive banks that closely approach a fully adjusted channel condition. If the discharge of a stream is very steady, a relatively small suspended-sediment load may be sufficient to provide approximate equilibrium; flashier streams require larger suspended-sediment concentrations to approximate adjusted channel conditions. The data of table 4 suggest, as examples, that the sediment loads and regularity of discharges of the rain-forest rivers in New Guinea are adequate to produce relative channel equili- brium. Despite comparatively steady flow rates, the spring-effluent channels in southern Missouri are slightly wider than would otherwise be expected due to the lack of suspended sediment.

\section{DISCUSSION}

The importance of silt and clay sediment sizes in providing strength or cohesiveness to the material forming a soil or channel perimeter has been demonstrated by a variety of studies. Schumm (1960, p. 21) demonstrated a power relation between geometry, as width-depth ratio, and a weighted silt-clay content of channel material. An especially pertinent engineering approach is a study by Trask (1959), which shows that the principal variables of soil strength are water content, clay mineralogy, ratio of clay content to larger particle sizes, and the particle sizes of the sediment comprising the non-clay fraction. Numerous laboratory tests made for the study demonstrated that when other variables are held constant, the shear strength of a silica soil is increased steadily and significantly by increasing proportions of clay. Furthermore, the lowest soil strengths of a mixture of 20 percent kaolin and 80 percent variable sand sizes were associated with the largest sand sizes; between the sand sizes of 0.35 and $1.68 \mathrm{~mm}$, however, a relatively small difference in soil strength was noted (Trask, 1959, p. 573-577).

Studies such as those of Schumm (1960) and Trask (1959) suggest that the shear strengths of materials forming a channel perimeter vary with the particle sizes transported by a stream. Thus, such studies provide explanations for the inconsistent results of the table 4 data in figures 17 through 22. A fully adjusted condition (state of equilibrium) commonly is regarded as one in which a net balance occurs between the shear strength of the channel material and the shear stress of the water-sediment mixture. In a specified time interval, therefore, the sediment eroded equals the sediment deposited, and through a channel reach lacking tributary inflow, the mass of sediment inflow balances the outflow. An additional requirement proposed for a fully adjusted condition is that there must be a mass balance of the individual particle sizes in the sediment load (Osterkamp and Harrold, 1982).

The principal independent variables that shape a channel are the water and sediment discharges and the topography that partially determines channel gradient. When, as described earlier and suggested by equations 28 and 29 , a net balance occurs between the shear stresses caused by the independent variables and the shear strengths of the channel material, a unique set of adjusted channel characteristics is assumed. This description of fluvial dynamics implies that a channel ad- 
justs its geometry to accommodate (1) the water and sediment discharges, (2) the gradient constraints imposed by topography, and (3) the fabric strength of the channel alluvium. In the derivation summarized by equations 28 and 29 , these changes are viewed not simply as an adjustment of geometry to imposed conditions of shear stress, but also as an adjustment of shear stresses, at the wetted perimeter, toward a limited range that prevails for all stable alluvial channels. As indicated by figure 1 and subject to the assumptions of this paper, the shear stresses near the edges of a rectangular channel section rapidly approach 0 regardless of the width-depth ratio. This means that the distribution of shear stresses tends to be similar along the wetted perimeters of all stable alluvial channels that approximate the rectangular shape assumed, in this paper, for a condition of constant discharge. Variation in width-depth ratio, which appears to be dependent on the sizes and sorting of the sediment supply, serves to adjust the maximum shear stress and water velocity in parts of the channel sections other than the wetted perimeter. This conclusion is supported indirectly by data showing that fluvial-sorting processes of bank material in most relatively stable alluvial channels result in particle-size distributions that are largely independent of the size, shape, or gradient of the channels (Osterkamp, 1981; Osterkamp and Harrold, 1982).

In summary, the derivation of this paper is based on width-depth ratios that imply specific shear-stress distributions. Dependent on the sediment-discharge characteristics and topographic constraints, the channel gradient and roughness adjust to produce water velocities and turbulence that maintain the requirement of sediment mass balance. For example, a wide range of channel gradients was found for channels with widthdepth ratios of 20 (Osterkamp and others, 1982). The streams of high gradient are very turbulent owing to armoring and high channel roughness, whereas those of low gradient are commonly sand- or gravel-bedded channels. Both types are assumed adjusted to flow rates roughly appoximating mean discharge, although the armor of the steep channels is moved only during relatively high flows. However, should large sediment sizes become unavailable for transport by the high-gradient stream, continued armoring is not possible. The necessary adjustment to maintain sediment mass balance then would be channel widening, an increase of the width-depth ratio, and a reduction of the maximum shear stress (fig. 1).

\section{CONCLUSIONS}

The derivation of the width and depth exponents in equations 24 and 25 is based on the continuity equation, the Manning equation, and an assumed relation describing the approximate manner in which shear-stress distributions of stable alluvial channels vary with channel geometry. The shapes of alluvial channels, however, are closely related to the sediment transported by streams and stored as material forming the bed and banks. Thus, the analytical approach of this paper indirectly considers the characteristics of channel sediment as an independent variable determining the downstream changes of channel morphology relative to water discharge. Unlike previous approaches that relate downstream changes in geometry and discharge as power functions with fixed exponents, the approach presented here results in variable power-function exponents (equations 1 to 5) that necessarily vary with the shape (and, therefore, also with the sediment characteristics) of alluvial channels.

Weaknesses of the approach described here include the assumptions necessary for the derivation of the exponents, such as a condition of constant discharge and a rectangular channel shape, and the need for iterative calibration by use of field data. Despite the weaknesses, however, the derived equations in this paper appear to relate the geometries of alluvial channels reasonably well to the mean discharges typical of those channels. The equations appear applicable to the entire range of natural alluvial channels, including those that are unusually wide or narrow relative to depth. The equations probably are not applicable to channels of ephemeral and intermittent streams or to channels that are not fully fluvial, such as those modified by tidal effects.

Although the assumptions necessary to the derivation of the exponents limit its application to natural stream channels, the forms of the equations derived in this paper are useful for understanding channel dynamics. Equation 17, for example, is based in part on the Manning equation, but perhaps it explains channel adjustments more effectively than the Manning equation. Because steady-state conditions are assumed, equation 17 shows that a change in any one of the variables must result in adjustment by one or more of the other variables in order to reachieve balanced channel conditions. The equation suggests that the balance between geometry and discharge necessary to maintain stable channel conditions is the result of a similar balance between the distribution of shear stresses along the channel perimeter and the channel properties.

Equation 17, therefore, suggests that if, at constant discharge and roughness, the gradient of a channel is increased, a likely result is some combination of increased width and critical shear stress. Conversely, as a channel reach develops smaller and smaller gradients through 
time (years to decades) because of increased meandering and channel length, there is a tendency toward smaller widths, smaller median particle sizes of the transported sediment and, hence, lower critical shear stresses. If the discharge is increased, expected changes are increased width and critical shear stresses and decreased gradient. The manner in which roughness changes with changes in channel width or discharge cannot be determined from equation 17 without considering the values of the various $j$ exponents.

Particularly for stream channels of high width-depth ratio, the data used for calibrating the derivation of the exponents presented in this paper are insufficient to yield trustworthy $b$ values. With additional geometrydischarge data from stable alluvial channels, especially those of high width-depth ratio, the accuracy of the calibration curve of figure 14 may be improved considerably. Certainly, further testing with field data seems necessary before the results of this paper can be considered reasonably reliable.

Perhaps the principal value of the equations derived in this paper is that they explain why a channel reach can exhibit markedly different physical properties through time while maintaining an approximate balance between total inflow and outflow of sediment. By relating water discharge to ranges of possible channel properties, the equations identify the ranges of expected stable conditions and thereby predict the general channel changes that will occur if stable conditions are not upset.

\section{REFERENCES CITED}

Ackers, Peter, and Charlton, F. G., 1971, The slope and resistance of small meandering channels: Proceedings, Institution of Civil Engineers, London, Supp. XV, 1970, Paper 7362S, p. 349-370.

Bathurst, J. C., 1979, Distribution of boundary shear stress in rivers, in Rhodes, D. D., and Williams, G. P., eds., Adjustments of the fluvial system: Dubuque, Iowa, Kendall-Hunt, p. 95-116.

Blench, Thomas, 1957, Regime behavior of canals and rivers: London, Butterworth's Scientific Publications, 138 p.

Brebner, Arthur, and Wilson, K. C., 1967, Derivation of the regime equations from relationships for pressurized flow by use of the principle of minimum energy-degradation rate: Proceedings, Institution of Civil Engineers, London, v. 36, Paper 6939, p. 47-62

Brush, L. M., 1961, Drainage basins, channels, and flow characteristics of selected streams in central Pennsylvania: U.S. Geological Survey Professional Paper 282-F, p. 145-181.

Burkham, D. E., 1972, Channel changes of the Gila River in Safford Valley, Arizona, 1846-1970: U.S. Geological Survey Professional Paper 655-G, $24 \mathrm{p}$.

Chow, V. T., 1959, Open-channel hydraulics: New York, McGraw-Hill, $680 \mathrm{p}$.

Engelund, Frank, and Hansen, Eggert, 1967, A monograph on sediment transport in alluvial streams: Teknisk Forlag, Copenhagen, $62 \mathrm{p}$.

Hedman, E. R., and Kastner, W. M., 1977, Stream-flow characteristics related to channel geometry in the Missouri River basin: U.S. Geological Survey Journal of Research, v. 5, no. 3, p. 285-300.
Hedman, E. R., and Oskterkamp, W. R., 1982, Streamflow characteristics related to channel geometry of streams in western United States: U.S. Geological Survey Water-Supply Paper 2193, 17 p..

Kartha, V. C., and Leutheusser, H. J., 1970, Distribution of tractive force in open channels: Journal of the Hydraulics Division, American Society of Civil Engineers, HY7, p. 1469-1483.

Kennedy, R. G., 1895, The prevention of silting in irrigation canals: Minutes of Proceedings of the Institution of Civil Engineers, London, v. 119, Paper 2826, p. 281-290.

Knighton, A. D., 1974, Variation in width-discharge relation and some implications for hydraulic geometry: Geological Society of America Bulletin, v. 85, p. 1069-1076.

Lacey, Gerald, 1930, Stable channels in alluvium: Minutes of Proceedings of the Institution of Civil Engineers, London, v. 229, Paper 4736, p. 259-384.

Lane, E. W., 1937, Stable channels in erodible material: American Society of Civil Engineers, Transactions, v. 102, p. 123-194.

- 1957, A study of the shape of channels formed by natural streams flowing in erodible material: U.S. Army Engineer Division, Missouri River, M.R.D., Sediment Series, no. 9, 106 p.

Lane, L. J., and Foster, G. R., 1980, Modeling channel processes with changing land use: Proceedings, American Society of Civil Engineers Symposium on Watershed Management, Boise, Idaho, v. 1, p. 200-214.

Langbein, W. B., 1964, Geometry of river channels: Proceedings, American Society of Civil Engineers, v. 90, p. 301-312.

Leopold, L. B., and Langbein, W. B., 1962, The concept of entropy in landscape evolution: U.S. Geological Survey Professional Paper $500-\mathrm{A}, 20 \mathrm{p}$.

Leopold, L. B., and Maddock, Thomas, Jr., 1953, The hydraulic geometry of stream channels and some physiographic implications: U.S. Geological Survey Professional Paper 252, 57 p.

Li Ruh-ming, 1974, Mathematical modeling of response from small watershed: Fort Collins, Colorado State University, Ph.D. thesis, $155 \mathrm{p}$.

Limerinos, J. T., 1969, Determination of the Manning coefficient from measured bed roughness in natural channels: U.S. Geological Survey Open-File Report, $79 \mathrm{p}$.

Lindley, E. S., 1919, Regime channels: Proceedings, Punjab Engineering Congress, Lahore, v. 7, p. 63-74.

Mosley, M. P., 1981, Semi-determinate hydraulic geometry of river channels, South Island, New Zealand: Earth Surface Processes and Landforms, v. 6, p. 127-137.

Osterkamp, W. R., 1978, Gradient, discharge, and particle-size relations of alluvial channels in Kansas, with observations on braiding: American Journal of Science, v. 278, p. 1253-1268.

1980, Sediment-morphology relations of alluvial channels: Proceedings, American Society of Civil Engineers Symposium on Watershed Management, Boise, Idaho, v. 1, p. 188-199.

1981, Bimodal particle-size distributions and sorting processes of alluvial-channel banks, in Particle motion and sediment transport, measurement techniques, and experimental results - extended abstracts: International Association for Hydraulic Research, Rapperswil, Switzerland, p. 52.1-52.7.

Osterkamp, W. R., and Harrold, P. E., 1982, Dynamics of alluvial channels-a process model; in Modeling components of hydrologic cycle: Proceedings, International Symposium on Rainfall-Runoff Modeling, Water Resources Publications, Littleton, Colorado, p. 283-296.

Osterkamp, W. R., and Hedman, E. R., 1977, Variation of width and discharge for natural high-gradient stream channels: Water Resources Research, v. 13, no. 2, p. 256-258.

1982, Perennial-streamflow characteristics related to channel geometry and sediment in the Missouri River basin: U.S. Geological Survey Professional Paper 1242, $37 \mathrm{p}$. 
Osterkamp, W. R., Hedman, E. R., and Wiseman, A. G., 1982, Geometry, basin-characteristic, discharge, and particle-size data from gaged stream-channel sites of the western United States: U.S. Geological Survey Hydrologic Data Open-File Report 82-93, $56 \mathrm{p}$.

Parker, Gary, 1979, Hydraulic geometry of active gravel rivers: American Society of Civil Engineers, Journal of the Hydraulics Division, HY9, p. 1185-1201.

Pickup, G., 1977, Computer simulation of the impact of the Wabo Hydroelectric Scheme on the sediment balance of the lower Purari: Purari River (Wabo) Hydroelectric Scheme Environmental Studies, v. 2, Office of Environment and Conservation, Papua, New Guinea.

Pickup, G., Higgins, R. J., and Warner, R. F., 1979, Impact of waste rock disposal from the proposed Ok Tedi mine on sedimentation processes in the Fly River and its tributaries: Department of Minerals and Energy, Papua, New Guinea.

Pickup, G., and Rieger, W. A., 1979, A conceptual model of the relationship between channel characteristics and discharge: Earth Surface Processes, v. 4, p. 37-42.

Prasad, S. N., and Alonso, C. V., 1976, Integral-equation analysis of flows over eroding beds: Proceedings, American Society of Civil Engineers Symposium on Inland Waterways for Navigation, Flood Control, and Water Divisions, Fort Collins, Colorado, v. 1, p. 760-772.

Replogle, J. A., and Chow, V. T., 1966, Tractive-force distribution in open channels: Journal of the Hydraulics Division, American Society of Civil Engineers, HY7, p. 169-189.

Rohlf, R. A., and Meadows, M. E., 1980, Dynamic mathematical modeling of rill erosion: Proceedings, American Society of Civil Engineers Symposium on Watershed Management, Boise, Idaho, v. 1, p. $13-26$.

Schumm, S. A., 1960, The shape of alluvial channels in relation to sediment type: U.S. Geological Survey Professional Paper 352-B, $30 \mathrm{p}$.

1968, River adjustment to altered hydrologic regimenMurrumbidgee River paleochannels, Australia: U.S. Geological Survey Professional Paper 598, 65 p.

Schumm, S. A., and Lichty, R. W., 1963, Channel widening and floodplain construction along Cimarron River in southwestern Kansas: U.S. Geological Survey Professional Paper 352-D, p. 71-88.

Smith, T. R., 1974, A derivation of the hydraulic geometry of steadystate channels from conservation principles and sediment transport laws: Journal of Geology, v. 82, p. 98-104.

Task Committee of the American Society of Civil Engineers, 1982, Relations between morphology of small streams and sediment yield: Journal of the Hydraulics Division, American Society of Civil Engineers, HY11, p. 1328-1365.

Tou Kuo-jen, 1964, Hydromorphology of alluvial channels of lowland rivers and tidal extuaries [English translation from Naval Oceanographic Office, Washington, D.C.l: Shuili Hwei Pao, no. 2, 23 p.

Trask, P. D., 1959, Effect of grain size on strength of mixtures of clay, sand, and water: Geological Society of America Bulletin, v. 70, p. 569-579.

Webber, E. E., and Roberts, J. M., 1981, Flood-flow characteristics related to channel geometry in Ohio: U.S. Geological Survey OpenFile Report 81-1105, $28 \mathrm{p}$.

Williams, G. P., 1978, Hydraulic geometry of river cross sectionstheory of minimum variance: U.S. Geological Survey Professional Paper 1029, $47 \mathrm{p}$.
Wolman, M. G., 1955, The natural channel of Brandywine Creek, Pennsylvania: U.S. Geological Survey Professional Paper 271, $50 \mathrm{p}$.

Wolman, M. G., and Brush, L. M., Jr., 1961, Factors controlling the size and shape of stream channels in coarse noncohesive sands: U.S. Geological Survey Professional Paper 282-G, p. 183-210.

\section{APPENDIX}

[List of numbered equations provided in the text]

Equation Equation Page

number

1. $W=a Q^{b}$

2. $D=c Q^{f}$

3. $V=k Q^{m}$

4. $G=t Q^{z}$

5. $n=r Q^{y}$

6. $b+f+m=1$

7. $Q_{i}=W D V$

8. $Q_{i}=k^{\prime} Q_{i}{ }^{b} Q_{i}^{f} Q_{i}{ }^{m}$

9. $\tau_{m} / \bar{\tau}=1+(W / D)^{-0.60}$

10. $Q=-{ }_{n}^{\psi} G^{1 / 2} W D^{5 / 3} \ldots$

11. $W^{3 / 5} D=\left[\frac{n Q}{\psi G^{1 / 2}}\right]^{3 / 5}$

12. $\mathrm{X}_{*}=x / P$

13. $\tau\left(x_{*}\right) / \bar{\tau}=F\left(x_{*}\right)$

14. $\tau\left(x_{*}\right) / \bar{\tau}=p\left(x_{*}\right)^{d}$

15. $\tau_{c} / \gamma G D=p(D / W)^{d}$

16. $W=\left[\begin{array}{c}\gamma G p \\ \tau_{c}\end{array}\right]^{\left(\frac{5}{8 d+3}\right)}\left[\frac{n Q}{\psi G^{1 / 2}}\right]^{\left(\frac{3 d+3}{8 d+3}\right)} \ldots 6$

17. $W=\psi^{-j} 1(p \gamma)^{j_{2}} \tau_{c}^{-j_{2}} G^{i_{3}} n^{j_{1}} Q^{j_{1}}$

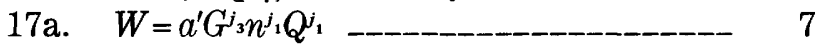

18. $D=\psi^{-j_{4}}(p \gamma)^{-j_{5}} \tau_{c}^{j_{5}} G^{-j_{6}} n^{j_{4}} Q^{j_{4}} \ldots$

18a. $D=c^{\prime} G^{-j_{6}} n^{j_{4}} Q^{j_{4}}$

19. $\bar{\tau}=\frac{1}{0.5} \int_{0}^{0.5} \tau\left(x_{*}\right) d x_{*}$

20. $p=2^{d}(d+1)-1(\tau)$

21. $\left(\tau_{m} / \bar{\tau}\right)=p(0.5)^{d}$

22. $d=\left(\tau_{m} / \bar{\tau}\right)-1.0$

23. $d=(W / D)^{-0.60}$

24. $W=a Q^{\left(j_{1}+z j_{3}+y j_{1}\right)}$

25. $D=c Q^{\left(j_{4}-z j_{6}+y j_{4}\right)}$

26. $\quad C \sim \frac{R}{n}^{0.167}$

27. $y=-0.167 f$

28. $\bar{\tau}=F\left(Q_{i}\right) \ldots 13$

29. $\left[W, D, G, n, d_{50}, S C, \ldots\right]^{1 / 2} \mathrm{~F}\left(Q_{i}\right) \ldots \ldots$ 
